\title{
Biochemical Characterization of a Novel Monospecific Endo- $\beta-1,4-G$ lucanase Belonging to GH Family 5 From a Rhizosphere Metagenomic Library
}

\author{
Anna Wierzbicka-Wos'1,2, Ruth Henneberger ${ }^{1,3}$, Ramón Alberto Batista-Garcia ${ }^{4}$, \\ Liliana Martínez-Ávila ${ }^{4}$, Stephen A. Jackson ${ }^{1,5}$, Jonathan Kennedy ${ }^{6}$ and \\ Alan D. W. Dobson ${ }^{1,5 *}$
}

\begin{abstract}
'Environmental Research Institute, University College Cork, Cork, Ireland, ${ }^{2}$ Department of Microbiology, Faculty of Biology, University of Szczecin, Szczecin, Poland, ${ }^{3}$ Institute for Molecular Health Sciences, ETH Zürich, Zurich, Switzerland, ${ }^{4}$ Centro de Investigación en Dinámica Celular, Instituto de Investigación en Ciencias Básicas y Aplicadas, Universidad Autónoma del Estado de Morelos, Cuernavaca, Mexico, ${ }^{5}$ School of Microbiology, University College Cork, Cork, Ireland, ${ }^{6}$ Centre for Process Innovation, Wilton, United Kingdom
\end{abstract}

OPEN ACCESS

Edited by:

José E. Barboza-Corona University of Guanajuato, Mexico

Reviewed by:

Keun-Sung Kim,

Chung-Ang University, South Korea Tania Pozzo,

University of California, Davis, United States

*Correspondence: Alan D. W. Dobson a.dobson@ucc.ie

Specialty section: This article was submitted to Microbiotechnology, Ecotoxicology and Bioremediation,

a section of the journa Frontiers in Microbiology

Received: 20 February 2019 Accepted: 29 May 2019

Published: 14 June 2019

Citation:

Wierzbicka-Woś A, Henneberger R, Batista-García RA, Martínez-Ávila L, Jackson SA, Kennedy J and Dobson ADW (2019) Biochemical Characterization of a Novel Monospecific Endo- $\beta$-1,4-Glucanase Belonging to GH Family 5 From a Rhizosphere

Metagenomic Library.

Front. Microbiol. 10:1342. doi: 10.3389/fmicb.2019.01342
Cellulases have a broad range of different industrial applications, ranging from food and beverages to pulp and paper and the biofuels area. Here a metagenomics based strategy was used to identify the cellulolytic enzyme CelRH5 from the rhizosphere. CelRH5 is a novel monospecific endo- $\beta-1,4$-glucanase belonging to the glycosyl hydrolase family 5 (GH5). Structural based modeling analysis indicated that CelRH5 is related to endo- $\beta-1,4$-glucanases derived from thermophilic microorganisms such as Thermotoga maritima, Fervidobacterium nodosum, and Ruminiclostridium thermocellum sharing 30-40\% amino acid sequence identity. The molecular weight of the enzyme was determined as $40.5 \mathrm{kDa}$. Biochemical analyses revealed that the enzyme displayed good activity with soluble forms of cellulose as a substrate such as ostazin brilliant red hydroxyethyl cellulose (OBR-HEC), carboxymethylcellulose (CMC), hydroxyethyl cellulose (HEC), and insoluble azurine cross-linked hydroxyethylcellulose (AZCL-HEC). The enzyme shows highest enzymatic activity at $\mathrm{pH} 6.5$ with high $\mathrm{pH}$ tolerance, remaining stable in the $\mathrm{pH}$ range 4.5-8.5. Highest activity was observed at $40^{\circ} \mathrm{C}$, but CelRH5 is psychrotolerant being active and stable at temperatures below $30^{\circ} \mathrm{C}$. The presence of the final products of cellulose hydrolysis (glucose and cellobiose) or metal ions such as $\mathrm{Na}^{+}, \mathrm{K}^{+}, \mathrm{Li}^{+}$, and $\mathrm{Mg}^{2+}$, as well as ethylenediaminetetraacetic acid (EDTA), urea, dithiothreitol (DTT), dimethyl sulfoxide (DMSO), 2-mercaptoethanol (2-ME) or glycerol, did not have a marked effect on CelRH5 activity. However, the enzyme is quite sensitive to the presence of $10 \mathrm{mM}$ ions $\mathrm{Zn}^{2+}, \mathrm{Ni}^{2+}, \mathrm{Co}^{2+}, \mathrm{Fe}^{3+}$ and reagents such as $1 \mathrm{M}$ guanidine $\mathrm{HCl}, 0.1 \%$ sodium dodecyl sulfate (SDS) and $20 \%$ ethanol. Given that it is psychrotolerant and retains activity in the presence of final cellulose degradation products, metal ions and various reagents, which are common in many technological processes; CelRH5 may be potential suitability for a variety of different biotechnological applications.

Keywords: functional metagenomic, cellulases, glycosyl hydrolase family $\mathbf{5}$, endoglucanase, psychrotolerant cellulolytic enzyme 


\section{INTRODUCTION}

Cellulases are extensively used in a variety of different industrial sectors including the healthcare, food, beverage, textile, pulp and paper sectors, as well as more recently in the biofuels sector (Sukumaran et al., 2005; Zhang and Kim, 2010; Kuhad et al., 2011; Bashir et al., 2014; Lambertz et al., 2014; Meneses et al., 2016). With the ever increasing demand on our rapidly depleting fossil fuel supply, the production of second generation biofuels from abundant lignocellulosic biomass sources such as agricultural and forestry wastes has become attractive as a sustainable and alternative option (Tiwari et al., 2018). Enzymatic lignocellulose hydrolysis using cellulases is one of the key steps in biofuel production from lignocellulosic biomass. Due to this, the global market for biofuel enzymes continues to increase and will reach $\$ 1.0$ billion by 2020 , with the European market alone set to be worth $\$ 325.2$ million in the same year ${ }^{1}$.

Cellulases are produced not only by plants and some insects feeding on cellulose, but also by a broad group of microorganisms including fungi, bacteria (Pérez et al., 2002; Sukumaran et al., 2005; Zhang and Kim, 2010; Kuhad et al., 2011; Lambertz et al., 2014; Meneses et al., 2016) and archaea (Graham et al., 2011). They are glycosyl hydrolases $(\mathrm{GH})$ (including $\beta$-glucosidase, endo- and exoglucanase) that catalyze the degradation of cellulose into glucose and other fermentable sugars. Exoglucanases (EC 3.2.1.91 and 3.2.1.176) progressively act on reducing and non-reducing ends of the cellulose to release cellobiose moieties. Endoglucanases (EC 3.2.1.4) randomly cleave internal $\beta$-1,4-glucan linkages, while $\beta$-glucosidases (EC 3.2.1.21) degrade di-saccharides to release glucose units. These enzymes are typically produced in prokaryotes as multi-enzymes complexes called cellulosomes (Pakarinen et al., 2014; Sharma et al., 2016).

Given the aforementioned demand for biofuel, there is an ongoing interest in the discovery of novel cellulases and enzymes which decompose plant biomass. In particular, cellulases that possess high catalytic activity on insoluble substrates, coupled with higher tolerance to end-product inhibition, are attractive from an industrial perspective (Ryu and Karim, 2011). While cellulases with industrially relevant characteristics have previously been obtained from cultured microorganisms, there is still a need for cellulases that are resistant to biomass pre-treatment conditions, such as high temperature and acid/alkaline conditions, among others (Horn et al., 2012; Mori et al., 2014; Vester et al., 2014). In this context, culture-independent metagenomics based approaches are increasingly being employed to discover novel cellulases with new biochemical properties, using both sequence and functional based approaches (Xing et al., 2012; Garg et al., 2016; Yang et al., 2016). Functional approaches do not depend on the availability of prior sequence information to detect cellulases and therefore there is greater potential to discover genetic novelty. These approaches have resulted in the identification of cellulases from compost, rumen, soil,

${ }^{1}$ https://www.reportbuyer.com/product/3392475 and decaying wood metagenomes, as these environments are rich in microbial consortia which efficiently decompose plant biomass (Allgaier et al., 2010; Li et al., 2011; Ferrer et al., 2012; Nacke et al., 2012). Also, the rhizosphere, a narrow zone surrounding and influenced by plant roots, is considered to be one of the most complex ecosystems on Earth. Moreover, the rhizosphere microbiome may reach cell densities much greater than the number of plant cells and when comparing the numbers of genes present, microbial genes far outnumber the plant genes present. Furthermore, glycosyl hydrolases which decompose cellulose are very abundant in soils including in the rhizosphere (Mendes et al., 2013; Berlemont and Martiny, 2016). With this in mind, we set out to assess the potential to identify novel cellulases from a metagenomic library obtained from rhizosphere soil samples collected from a non-fertilized grassland, using a functional based approach. Following screening of approximately 15,600 clones, three positive clones were identified on LB (Luria Bertani) medium supplemented with ostazin brilliant red $\mathrm{H}-3 \mathrm{~B}$ hydroxyethyl cellulose (OBR-HEC). One of these clone, named as RH5_TO-NF021-E23, displayed the best activity and the enzyme was subsequently biochemically characterized following heterologous expression in Escherichia coli. The recombinant CelRH5 was found to be a novel monospecific endo- $\beta$ 1,4-glucanase belonging to $\mathrm{GH}$ family 5 (GH5). CelRH5 displayed enzymatic activity in the presence of OBR-HEC, carboxymethylcellulose (CMC), hydroxyethyl cellulose (HEC), azurine-cross-linked hydroxyethyl cellulose (AZCL-HEC), and was active over a broad $\mathrm{pH}$ range (4.5-8.5), with an optimal activity at $\mathrm{pH}$ 6.5. The enzyme also showed tolerance to low temperatures being functional and stable below $30^{\circ} \mathrm{C}$ and activity was not inhibited by either glucose or cellobiose. Cellulase activity was not affected by the addition of various metal ions such as $\mathrm{Na}^{+}, \mathrm{K}^{+}, \mathrm{Li}^{+}$, and $\mathrm{Mg}^{2+}$. In addition, ethylenediaminetetraacetic acid (EDTA), urea, dithiothreitol (DTT), dimethyl sulfoxide (DMSO), 2-mercaptoethanol (2-ME) and glycerol did not affect the activity of the recombinant CelRH5 enzyme.

\section{MATERIALS AND METHODS}

\section{Sampling and Metagenomic Library Construction}

Rhizosphere samples (1-5 cm below the surface) were collected from non-fertilized grassland surrounding an organic field trial site at the Teagasc Oak Park (Carlow, Ireland, 52.8657 $\left.\mathrm{N}, 6.9129^{\circ} \mathrm{W}\right)$. Soil samples (TO-NF) were collected and handled with sterile, DNA-free tools (treated with 5\% sodium hypochlorite for $30 \mathrm{~min}$ prior to washing and autoclaving) and stored in sterile, DNA-free plastic containers. Samples were transported to the laboratory on ice, aseptically fractionated and stored at $4^{\circ} \mathrm{C}$ until further processing.

High molecular weight (HMW) metagenomic DNA was extracted, purified and a metagenomic library was constructed using the CopyControl ${ }^{\mathrm{TM}}$ Fosmid Library Production Kit pCC1FOS (Epicentre Biotechnologies) as previously described (O’Mahony et al., 2015). Approximately 45,000 clones were 
picked with the Genetix Qpix2 XT robotic system (Genetix, New Milton, United Kingdom) into 384-well plates containing LB media ( $1 \%$ peptone, $1 \% \mathrm{NaCl}, 0.5 \%$ yeast extract; $\mathrm{pH} 7.0$ ) enriched with: $6.3 \mathrm{~g} / \mathrm{L} \mathrm{K}_{2} \mathrm{HPO}_{4}, 1.8 \mathrm{~g} / \mathrm{L} \mathrm{KH}_{2} \mathrm{PO}_{4}, 0.5 \mathrm{~g} / \mathrm{L}$ sodium citrate dihydrate, $0.09 \mathrm{~g} / \mathrm{L} \mathrm{MgSO}_{4} \times 7 \mathrm{H}_{2} \mathrm{O}, 6 \%(\mathrm{v} / \mathrm{v})$ glycerol. After the incubation at $37^{\circ} \mathrm{C}$ for $18-20 \mathrm{~h}$, the library was stored at $-80^{\circ} \mathrm{C}$.

To determine the average insert size, twelve recombinant fosmid clones were randomly picked, used in NotI digestion reactions and analyzed by Pulsed-Field Gel Electrophoresis (PFGE) with the following conditions: $1 \%$ agarose in $0.5 \%$ Tris-Borate-EDTA (TBE) buffer, $6 \mathrm{~V} / \mathrm{cm}, 1-25 \mathrm{~s}$ switch time, $120^{\circ}$ angle, $11.5 \mathrm{~h}$ and $14^{\circ} \mathrm{C}$. Six randomly selected fosmid clones were end-sequenced using the $\mathrm{pCC} 1^{\mathrm{TM}} / \mathrm{pEpiFOS}{ }^{\mathrm{TM}}$ forward and reverse primer (Epicentre Biotechnologies). Sequencing was performed by GATC Biotech (Konstanz, Germany) and sequences were subjected to comparison with public databases using BLASTn algorithms ${ }^{2}$.

\section{Screening of Metagenomic Library Clones for Cellulase Activity}

Recombinant fosmid clones were tested for endoglucanase activity on LB agar plates supplemented with OBR-HEC (supplied by the Department of Chemistry, Slovak Academy of Science, Bratislava, Slovakia), a water-soluble cellulose with approximately $12.5 \%$ covalently bound dye. A $1 \%(\mathrm{w} / \mathrm{v})$ stock solution of OBR-HEC was prepared by stirring $1 \mathrm{~g}$ of OBR-HEC in $100 \mathrm{~mL}$ of Milli-Q $\mathrm{H}_{2} \mathrm{O}$ overnight in the dark, followed by autoclaving for $15 \mathrm{~min}$. This solution was combined with freshly autoclaved LB agar to a final concentration of $0.1 \%$ $\mathrm{OBR}-\mathrm{HEC}$ and $100 \mathrm{~mL}$ of this mixture was then poured into $20 \mathrm{~cm} \times 20 \mathrm{~cm}$ trays that contained $200 \mathrm{~mL}$ of solidified and cooled LB agar [containing $12.5 \mu \mathrm{g} / \mathrm{mL}$ chloramphenicol and $0.01 \%(\mathrm{w} / \mathrm{v})$ arabinose].

Approximately 15,600 fosmid clones were replicated into fresh LB medium supplemented with $12.5 \mu \mathrm{g} / \mathrm{mL}$ chloramphenicol and incubated at $37^{\circ} \mathrm{C}$ overnight. The clones were replicated onto the prepared OBR-HEC agar trays, using the QPix robotic system (Molecular Devices). Plates were incubated at $37^{\circ} \mathrm{C}$ overnight, followed by further incubation at $25^{\circ} \mathrm{C}$ for 4-5 days to enable detection of cellulolytic activity, i.e., zones of clearing around the colonies. E. coli EPI300 ${ }^{\mathrm{TM}} \mathrm{T} 1^{\circledR}$ clones containing pCC1FOS with cloned fosmid control DNA (Epicentre, $36 \mathrm{~kb}$ fragment of human DNA), were used as a negative control.

\section{Sequencing and Bioinformatic Analyses}

Recombinant fosmid RH5_TO-NF021-E23 displayed cellulolytic activity and was sequenced by Roche 454 pyrosequencing. A contiguous sequence of approximately $41 \mathrm{~kb}$ (partially including the fosmid sequence) was re-assembled by the University of Liverpool, Center for Genomic Research (United Kingdom). The sequence was analyzed for the presence of presumable open-reading frames (ORFs) using FGENESB - Bacterial Operon and Gene Prediction

\footnotetext{
${ }^{2}$ http://blast.ncbi.nlm.nih.gov/Blast.cgi
}

Program (Softberry, Goteborg, Sweden) and the MetaGene program (Noguchi et al., 2006). Nucleotide and amino acid sequences of identified ORFs were then screened using BLAST searches to establish their similarity to other sequences deposited in databases.

The amino acid sequence of the metagenome-derived cellulase CelRH5 was determined using the EMBOSS Transeq application (Rice et al., 2000; McWilliam et al., 2013; Li et al., 2015). To establish the most related nucleotide and amino acid sequences for the celRH5 gene, BLASTn, BLASTp, and PSI-BLATS analysis were performed (see text footnote 2 ). The theoretical molecular weight $\left(\mathrm{M}_{\mathrm{w}}\right)$ and isoelectric point $(\mathrm{pI})$ were estimated using the ExPASy ProtParam tool Compute MW/pI (Gasteiger et al., 2005). The prediction of functional and structural domains, catalytic sites and signal sequences was performed with applications such as Conserved Domain Database (CDD) (Marchler-Bauer et al., 2015), ScanProsite (De Castro et al., 2006), and SignalP 4.1 (Petersen et al., 2011). A prediction of the potential subcellular localization of CelRH5 in gram-negative bacteria was investigated using TargetP 1.1 (Emanuelsson et al., 2007). Phylogenetic analysis was performed using MEGA 6.0 (Tamura et al., 2013) to establish the phylogenetic relationship with other $\mathrm{GH} 5$ members, with the amino acid sequences of the most related proteins with CelRH5 being used in the phylogeny construction. In addition, other putative endoglucanases and cellulases recovered from the Protein Data Bank (PDB) (Berman et al., 2000), and previously characterized metagenome derived GH5 enzymes, were also included. Sequence alignment was prepared using ClustalW and the phylogenetic tree was constructed using the Maximum Likelihood Method and LG+G model with bootstrap 1000 .

\section{CeIRH5 Modeling}

To predict the structure and biological function of the CelRH5 protein, based on known proteins deposited in PDB, the CelRH5 amino acid sequence without the signal peptide was submitted to the automated comparative protein modeling iTASSER server (Roy et al., 2010) and a 3D model was obtained. The 3D superposition between CelRH5 and some structural neighbors (PDBs 3MMU, 1CEO, 4YHE, 3NCO, and 3RJX) was prepared using the VMD software (Humphrey et al., 1996).

\section{Cloning of the celRH5 Gene in E. coli}

The following primers were used to amplify the celRH5 gene and the signal peptide sequence, RH5flPciI (5'AAAACATGTACCCATCAAAAGCGACTGAAAGGC- $3^{\prime}$ ) and RH5rXhoI (5'-AAACTCGAGCAGTGCTCGCCTGATCGGC$3^{\prime}$ ) from the fosmid RH5_TO-NF-020-E23. Both primers contained recognition sites for endonucleases PciI and XhoI, respectively (underlined) and were designed to facilitate cloning into the expression vector $\mathrm{pBAD} / M y c$-His A (Invitrogen) under control of the arabinose inducible promoter $\mathrm{P}_{\mathrm{BAD}}$. Two final codons in the gene sequence were modified by replacing the sequence $5^{\prime}$-CTGGAT sequence with $5^{\prime}$-CTCGAG (italic) to generate a XhoI restriction site, resulting in a silent mutation without changing the amino acid endoglucanase sequence, and the terminal stop codon was also removed to allow C-terminal 
fusion with the 6xHis-tag region of the vector. The PCR reaction used Dream Taq Polymerase (Thermo Scientific) under the following conditions: $95^{\circ} \mathrm{C}$ for $2 \mathrm{~min} ; 34$ cycles of denaturation at $95^{\circ} \mathrm{C}$ for $30 \mathrm{~s}$, primers hybridization at $63^{\circ} \mathrm{C}$ for $30 \mathrm{~s}$, primers elongation at $72^{\circ} \mathrm{C}$ for $1 \mathrm{~min}$; and $72^{\circ} \mathrm{C}$ for $5 \mathrm{~min}$.

The PCR amplified celRH5 gene was cloned into the pBAD/Myc-HisA vector following double digestion with NcoI and SalI and the recombinant plasmid was transformed into E. coli TOP10 (Invitrogen) cells, plated onto LB agar medium supplemented with L-arabinose ( $0.02 \%$ final concentration), carbenicillin (100 $\mu \mathrm{g} / \mathrm{mL}$ final concentration) and OBR-HEC as a chromogenic substrate $(0.1 \%$ final concentration), and cultivated at $37^{\circ} \mathrm{C}$ overnight. Recombinant E. coli TOP10/pBAD/celRH5 clones displaying cellulase activity were picked and transferred onto fresh selective LB agar plates. The inserted fragment in the recombinant plasmid was also sequenced by GATC Biotech using primers pBAD forward (5'-ATGCCATAGCATTTTTATCC- $\left.3^{\prime}\right)$ and pBAD reverse ( $5^{\prime}$-GATTTAATCTGTATCAGG-3') to confirm the sequence of the celRH5 gene in the $\mathrm{PBAD} / \mathrm{Myc}$-HisA vector.

\section{Production of Recombinant Enzyme CelRH5 in E. coli}

To obtain the highest production yield of active CelRH5 enzyme while minimizing the amount of inactive fraction as inclusion bodies, the following procedure was developed. An E. coli TOP10/pBAD/celRH5 overnight culture was used to inoculate $150 \mathrm{~mL}$ of $\mathrm{LB}$ medium containing carbenicillin $(0.1 \mathrm{mg} / \mathrm{mL})$. Additional spiral coils were placed in the medium providing appropriate aeration. Cultures were grown shaking $(180 \mathrm{rpm})$ at $37^{\circ} \mathrm{C}$ until $\mathrm{OD}_{600}$ reached 0.55 . Expression was induced with $\mathrm{L}$-arabinose at a final concentration of $0.02 \%$ in the medium. Incubation was continued for a further $3 \mathrm{~h}$ at $20^{\circ} \mathrm{C}$ with shaking $(180 \mathrm{rpm})$ and the cells were then collected by centrifugation $\left(15 \mathrm{~min}, 10,000 \times g, 4^{\circ} \mathrm{C}\right)$ and frozen at $-20^{\circ} \mathrm{C}$.

\section{Purification of Recombinant Enzyme CelRH5}

Pellets obtained from $150 \mathrm{~mL}$ cultures were thawed and re-suspended in lysis buffer B-PER Bacterial Extraction Reagent (Thermo Scientific) supplemented with lysozyme and DNase I. Additionally cells disruption involved sonication on ice (five cycles for $60 \mathrm{~s}$ pulse and $30 \mathrm{~s}$ pause). Cell debris from the lysate was removed by centrifugation $(20 \mathrm{~min}, 10,000 \times g$, $4^{\circ} \mathrm{C}$ ) and the cell-free supernatant was diluted with equal volume of Equilibration Buffer (20 mM sodium phosphate, $300 \mathrm{mM}$ sodium chloride, $10 \mathrm{mM}$ imidazole; $\mathrm{pH}$ 7.4) and applied on re-equilibrated HisPur Ni-NTA Resin (Thermo Scientific) according to the manufacturer's protocol. Unbound proteins were washed out using Wash Buffer $(20 \mathrm{mM}$ sodium phosphate, $300 \mathrm{mM}$ sodium chloride, $25 \mathrm{mM}$ imidazole; $\mathrm{pH}$ 7.4). Elution Buffer (20 mM sodium phosphate, $300 \mathrm{mM}$ sodium chloride, $250 \mathrm{mM}$ imidazole; $\mathrm{pH}$ 7.4) was used to extract His-tag bound proteins from the resin. Fractions were combined and dialyzed in $20 \mathrm{mM}$ sodium phosphate buffer ( $\mathrm{pH}$ 6.5) for $24 \mathrm{~h}$ at $10^{\circ} \mathrm{C}$. The enzyme preparation was stored at $4^{\circ} \mathrm{C}$ for further analysis.

\section{Enzyme Assays}

Recombinant E. coli TOP10/pBAD/celRH5 clone able to produce metagenome-derived cellulase was used in activity assays on LB plates supplemented with L-arabinose $(0.02 \%$ final concentration), carbenicillin (100 $\mu \mathrm{g} / \mathrm{mL}$ final concentration) and various substrates $(0.1 \%$ final concentration $)$ such as soluble CMC, xylan from beech wood, arabic gum and insoluble Avicel (Sigma-Aldrich). Activity from recombinant clones was detected by staining plates, after incubation at $37^{\circ} \mathrm{C}$ for $24 \mathrm{~h}$, with $1 \%$ (w/v) Congo red dye and de-stained with $1 \mathrm{M} \mathrm{NaCl}$. Positive results were seen as a clear zone around the recombinant colonies. Clones were also tested with dyed substrates such as soluble OBR-HEC, Remazol Brilliant Blue-xylan (RBB-xylan) and insoluble AZCL-HEC, AZCL-xylan (Megazyme). Positive results were seen as a change in the ambient color of colonies. A negative control strain E. coli TOP10 transformed with plasmid $\mathrm{pBAD} / \mathrm{MycHis}$ A was used.

As a standard procedure to measure the recombinant enzyme CelRH5 activity, an assay with OBR-HEC solution as a substrate was performed (Biely et al., 1985; Ito et al., 2004). The reaction mixture contained $150 \mu \mathrm{L}$ of $0.33 \%$ OBR-HEC in $20 \mathrm{mM}$ sodium phosphate buffer ( $\mathrm{pH}$ 6.5) and $50 \mu \mathrm{L}$ of enzyme preparation. Incubation was carried out at $30^{\circ} \mathrm{C}$ for $30 \mathrm{~min}$. These parameters were then taken as the standard conditions. The reaction was stopped with $600 \mu \mathrm{L}$ of acetone and unprocessed substrate was removed by centrifugation for $5 \mathrm{~min}$ at $12,000 \times g$. The absorbance of the supernatant was measured at $550 \mathrm{~nm}$. One unit (U) of cellulase activity was defined as the amount of enzyme required to release low molecular weight product containing $1 \mu \mathrm{mol}$ of OBR from the dyed HEC per minute, under standard conditions.

The substrate specificity of the purified enzyme CelRH5 was determined at $30^{\circ} \mathrm{C}$ in $20 \mathrm{mM}$ phosphate buffer $(\mathrm{pH}$ 6.5) using various substrates. The cellulase activity toward such polysaccharides as CMC, HEC, Avicel, corn stover (Sigma-Aldrich), soluble and insoluble chitin from crab shells (Sigma-Aldrich) and beech wood xylan was assayed by measuring the amount of reducing sugars released from polysaccharide using dinitrosalicylic acid (DNS) according to the Miller's method and D-glucose was used as a standard (Miller, 1959). To measure the CelRH5 activity, reaction mixtures containing $100 \mu \mathrm{L}$ of enzyme preparation and $400 \mu \mathrm{L}$ of the appropriate substrate (1\% final concentration) in $20 \mathrm{mM}$ phosphate buffer ( $\mathrm{pH} 6.5$ ) was incubated at $30^{\circ} \mathrm{C}$ for $1 \mathrm{~h}$. The reaction was terminated by mixing $100 \mu \mathrm{L}$ of sample with $50 \mu \mathrm{L}$ of DNS and by incubation at $90^{\circ} \mathrm{C}$ for $5 \mathrm{~min}$. After that samples were cooled on ice and $500 \mu \mathrm{L}$ of distilled water was added. The cellulase activity was assayed by measuring the increase in absorbance at $490 \mathrm{~nm}$ owing to the release of reducing sugars from the substrates. One unit of cellulase specific activity was defined as the amount of enzyme required to hydrolyze the substrate and to release $1 \mu \mathrm{mol}$ of reducing sugars within $1 \mathrm{~min}$ per $1 \mathrm{mg}$ of protein. 
Beta-glucosidase, cellobiohydrolase, and $\beta$-xylosidase activities were determined using the respective chromogenic substrates $p$-nitrophenol-glucopyranoside $(p \mathrm{NPG}), \quad p$-nitrophenol-cellobioside $\quad(p \mathrm{NPC}) \quad$ and $p$-nitrophenol-xylopyranoside ( $p \mathrm{NPX})$ (Sigma-Aldrich) at $3 \mathrm{mM}$ concentrations in $20 \mathrm{mM}$ phosphate buffer $(\mathrm{pH}$ 6.5) were used. The activity of CelRH5 was assayed by measuring the increase in absorbance at $405 \mathrm{~nm}$ owing to the release of $p$-nitrophenol from the chromogenic substrates. One unit of enzyme activity was defined as the amount of enzyme liberating $1 \mu \mathrm{mol}$ of $p$-nitrophenol from the substrate in $1 \mathrm{~min}$ under the standard reaction conditions.

\section{Protein Determination and Molecular Weight Estimation}

The protein concentration in samples was determined according to the Bradford method using Coomassie Plus ${ }^{\mathrm{TM}}$ Assay kit (Thermo Scientific) and with bovine serum albumin (BSA) as a standard (Walker, 2002). All fractions from the purification step were also separated using $12 \%$ polyacrylamide gel electrophoresis in denaturing conditions according to the Laemmli method (Walker, 2002) to establish the purity of the enzyme preparation and molecular weight of the enzyme monomer. The samples, with denaturing loading buffer, were incubated at $95^{\circ} \mathrm{C}$ for $10 \mathrm{~min}$. Electrophoresis was performed for $150 \mathrm{~min}$ at $100 \mathrm{~V}$ at room temperature. To visualize proteins in the gel, staining with Coomassie Brilliant Blue was performed (Walker, 2002).

\section{Biochemical Characterization of CelRH5}

The purified enzyme CelRH5 was used to determine the specificity and different biochemical properties under various conditions. Reactions were carried out under standard conditions with OBR-HEC as a substrate, and the reaction was stopped after $30 \mathrm{~min}$ with acetone. Cellulase activity was examined by measuring the absorbance of dyed low molecular weight product released from OBR-HEC, as described above, as the standard procedure. In all activity assays CelRH5 preparations contained $0.03 \mathrm{mg}$ of enzyme per $1 \mathrm{~mL}$. All experiments were conducted in triplicate.

The optimum $\mathrm{pH}$ was determined by assaying the CelRH5 enzyme activity with OBR-HEC dissolved in $20 \mathrm{mM}$ Britton-Robinson buffer in $\mathrm{pH}$ values between 4.0 and 10.0 (with $0.5 \mathrm{pH}$ unit gradations). Enzyme in appropriate $\mathrm{pHs}$ was incubated at $20^{\circ} \mathrm{C}$ for $30 \mathrm{~min}$ and the reactions were stopped with acetone. Activity of the enzyme was measured using the standard procedure. The highest activity obtained during assays was defined as the control, and defined as $100 \%$ activity. The $\mathrm{pH}$ stability profiles were determined by incubating the enzyme

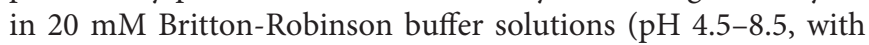
$1.0-\mathrm{pH}$ unit gradations) at $20^{\circ} \mathrm{C}$ up to $24 \mathrm{~h}$ with two checkpoints after $1 \mathrm{~h}$ and $7 \mathrm{~h}$. Enzyme activity during incubation was established under standard conditions. Activity of the enzyme obtained at $0 \mathrm{~h}$ was defined as the control (100\% activity).

The thermo-dependency of CelRH5 was assayed at various temperatures between 0 and $90^{\circ} \mathrm{C}$ (with $10^{\circ} \mathrm{C}$ gradations) by preparing samples as described in standard procedure and by incubation of the reaction mixture at appropriate temperatures for $30 \mathrm{~min}$. The highest activity obtained during assay was defined as the control and was defined as $100 \%$ activity. The thermostability profiles were determined by incubating the enzyme at appropriate temperatures $4^{\circ} \mathrm{C}, 10^{\circ} \mathrm{C}, 20^{\circ} \mathrm{C}, 30^{\circ} \mathrm{C}$, $40^{\circ} \mathrm{C}$, and $50^{\circ} \mathrm{C}$ up to $54 \mathrm{~h}$ with two checkpoints after $2 \mathrm{~h}$ and $6 \mathrm{~h}$. Enzyme activity during this experiment was determined by removing aliquots from the incubating sample and then by using the standard enzyme activity assays previously described.

The effect of various metal ions $\left(\mathrm{Na}^{+}, \mathrm{K}^{+}\right.$in 1,10 and $100 \mathrm{mM}$ concentrations, and $\mathrm{Li}^{+}, \mathrm{Mn}^{2+}, \mathrm{Mg}^{2+}, \mathrm{Ca}^{2+}, \mathrm{Zn}^{2+}, \mathrm{Ni}^{2+}$, $\mathrm{Co}^{2+}, \mathrm{Fe}^{3+}$ in 1 and $10 \mathrm{mM}$ concentrations), final products of cellulose hydrolysis (glucose and cellobiose in 1, 10 and $100 \mathrm{mM}$ concentrations) and other selected reagents (urea, guanidine $\mathrm{HCl}$, DTT, glycine, SDS, 2-ME, DMSO, glycerol, ethanol and EDTA in various concentrations) (Figure 9C) on enzyme CelRH5 activity was determined by pre-incubating the enzyme with the individual reagents in $20 \mathrm{mM}$ sodium phosphate buffer $(\mathrm{pH}$ 6.5) for $1 \mathrm{~h}$ followed by activity determination under standard conditions. Samples without metal ions and tested reagents were defined as controls representing $100 \%$ activity.

The kinetic parameters of freshly purified enzyme were established at $30^{\circ} \mathrm{C}$ using OBR-HEC as a substrate (in final concentrations of $0.75,1.5,3.0,4.5,6.0$, and $7.5 \mathrm{mg} / \mathrm{mL}$ ), diluted in $20 \mathrm{mM}$ sodium phosphate buffer $(\mathrm{pH}$ 6.5). To determine Michaelis constant $\left(K_{\mathrm{m}}\right)$, maximal velocity $\left(V_{\max }\right)$ and catalytic constant $\left(k_{\text {cat }}\right)$ for the enzyme, CelRH5 reaction rate versus substrate concentration were plotted and calculated using Michaelis-Menten model with the GraphPad Prism 7.02 for Windows application.

\section{Statistical Calculations}

The arithmetic mean and the standard deviations were calculated. Simple classification variance analysis (ANOVA) tests were applied to determine significant differences. Firstly, the analysis of homogeneity of variance and normal distribution were performed by Hartley-Cochran-Bartlett and Kolmogorov-Smirnov tests, respectively. Subsequently ANOVAs were conducted to demonstrate the similarities or statistical differences between data. Finally, Tukey HSD tests was performed for the post hoc analyses. All statistical calculations were performed in STATISTICA 13.1.

\section{RESULTS}

\section{Metagenomic Library Construction and Screening Cellulase Clones}

From 45,000 total clones of the TO-NF soil metagenomic library approximately 15,600 clones were screened for cellulolytic activity. One very strongly positive clone RH5_TO-NF021-E23 was observed and this was confirmed by re-plating the clone on LB agar plates with OBR-HEC where a strong zone of clearance was observed. Moreover, the cellulase activity was also observed after re-transformation of the isolated fosmid into fresh E. coli EPI300 ${ }^{\mathrm{TM}}$ cells. The fosmid from the RH5-TO-NF021-E23 clone, which contained an insert of 33,291 bp, was then sequenced 
and was found to contain 30 putative ORFs (Supplementary Figure 1A). The homology to other proteins and conserved domains were determined using the BLASTp and CDD applications, respectively (Supplementary Table 1), with ORF 23, 1,080 bp in length, showing similarity with endo-1,4-glucanases belonging to the GH5 family. The deduced product of gene celRH5 consisted of 359 amino acid residues with a calculated molecular mass of $40.5 \mathrm{kDa}$ and an isoelectric point of 7.7. The CelRH5 amino acid sequence of the metagenome-derived cellulase appears to be enclosed within one catalytic domain containing 268 amino acid residues and CelRH5 appears to contain a signal peptide of 31 amino acids (Supplementary Figure 1B). Analysis with SignalP-4.1 and Target P1.1 suggested that the cleavage site is likely to be located between position Ala31 and Gln32 (Emanuelsson et al., 2007).

However, no carbohydrate-binding module (CBM), which is often present in cellulose degrading enzymes, could be identified. Using ScanProsite the catalytic site appears to be present from aa 238 to 247 within the conserved signature sequence LLFELLNEPH with the conserved glutamic acid at position 245 (Figure 1).

Sequence analyses of the putative cellulase celRH5 gene with BLASTn revealed no significant nucleotide similarity to known cellulases with only $66 \%$ and $68 \%$ relative identities being observed with putative endoglucanases from Ramlibacter tataouinensis 5-10 and Ramlibacter tataouinensis TTB310, respectively (data not shown). In addition, amino acid sequence analysis did not show very high homology with previously reported and characterized cellulases derived from cultivable microorganisms (Table 1). The most significant similarity with NCBI reference protein sequences was mainly exhibited by putative proteins with the highest hits of 65-66\% of identity for Ramlibacter tataouinensis spp. (WP_061501559.1, WP_013900354.1) and Caenimonas sp. SL110 (WP_048440605.1). Moreover, analyses with BLASTp based on PDB were performed to determine the similarities to biochemically and structurally characterized cellulases. Results showed that CelRH5 displayed the highest similarity with the endo- $\beta$-1,4-endoglucanase TmCel5A from Thermotoga maritima, FnCel5A from Flavidobacterium nodosum Rt17B1, and Ctcel5e from Ruminiclostridium thermocellum ATCC 27405 with CelRH5, sharing 39\%, $36 \%$, and $34 \%$ identity, respectively (Chhabra et al., 2002; Mahadevan et al., 2008; Pereira et al., 2010; Wang et al., 2010; Yuan et al., 2015). Phylogenetic analysis of amino acid sequences obtained with MEGA 6.0 revealed that the CelRH5 cellulase had the highest homology to putative endoglucanases from the Beta-proteobacteria group belonging to the Comamonadaceae family (Figure 2). These results are in agreement with those obtained from the ORFs analyses on the metagenomic DNA fragment from the RH5_TO-NF021-E23 clone (Supplementary Table 1).

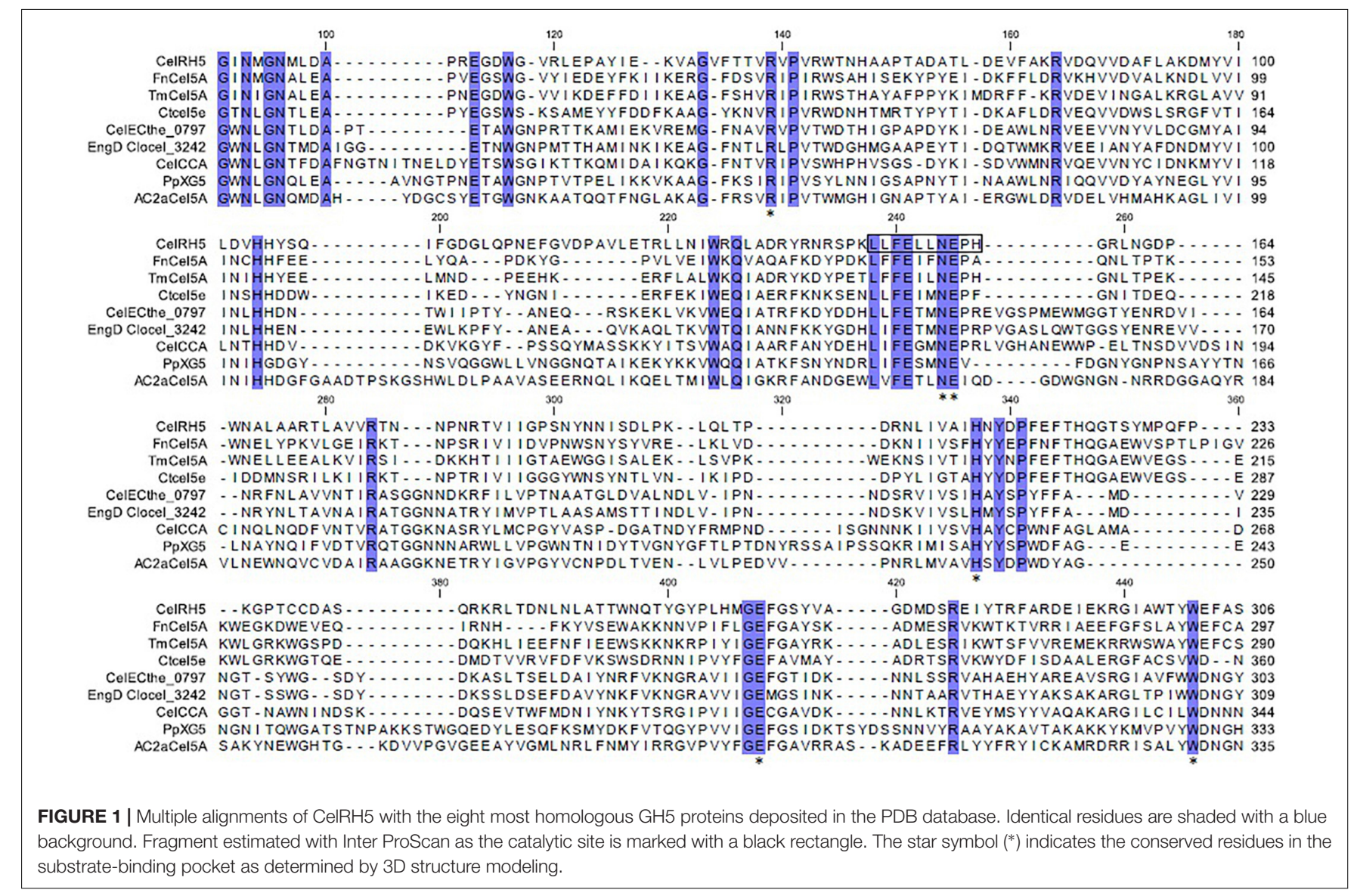


TABLE 1 | Amino acid sequence CeIRH5 homology to other sequences deposited in database established using BLASTp.

\begin{tabular}{|c|c|c|c|}
\hline Most homologous microorganism & Query cover & Identity & Accession no. \\
\hline Ramlibacter tataouinensis ${ }^{a}$ & $94 \%$ & $65 \%$ & WP_061501559.1 \\
\hline Ramlibacter tataouinensis ${ }^{a}$ & $91 \%$ & $66 \%$ & WP_013900354.1 \\
\hline Caenimonas sp. SL110 a & $83 \%$ & $68 \%$ & WP_048440605.1 \\
\hline Thermotoga maritima ${ }^{\mathrm{b}}$ & $93 \%$ & $39 \%$ & 3MMU, 3AZR, 3AMG, 3AOF \\
\hline Flavidobacterium nodosum Rt17B1 ${ }^{b}$ & $93 \%$ & $36 \%$ & 3RJX, 3RJX, 3NCO \\
\hline Ruminiclostridium thermocellum ATCC $27405^{b}$ & $87 \%$ & $32-34 \%$ & 5BYW, 4U3A, 4U5I \\
\hline Ruminiclostridium thermocellumb & $95 \%$ & $31 \%$ & $4 \mathrm{IM} 4$ \\
\hline Uncultured bacterium ${ }^{b}$ & $61-62 \%$ & $31 \%$ & 4W84, 4W85, 4W86 \\
\hline Bacillus licheniformis ${ }^{b}$ & $86 \%$ & $28 \%$ & $4 Y Z P$ \\
\hline Piromyces rhizinflatus ${ }^{b}$ & $88 \%$ & $26 \%$ & 3AYR, 3AYS \\
\hline Paenibacillus pabulib & $80 \%$ & $25 \%$ & 2JEP \\
\hline Bacteroides bacterium AC2a ${ }^{b}$ & $93 \%$ & $25 \%$ & 4YHE, 4YHG \\
\hline Clostridium cellulovorans ${ }^{b}$ & $94 \%$ & $24 \%$ & 3NDY, 3NDZ \\
\hline Clostridium cellulolyticum $\mathrm{H}_{10}$ & $92 \%$ & $23 \%$ & $1 E D G$ \\
\hline Bacteroides ovatus ${ }^{b}$ & $98 \%$ & $22 \%$ & 3ZMR \\
\hline
\end{tabular}

a Sequences selected with BLASTp based on NCBI Protein Reference Sequences. ${ }^{b}$ Sequences selected with BLASTp based on PDB protein database and i-TASSER.

\section{In silico Structural Analysis of CelRH5}

In an attempt to obtain a three-dimensional (3D) model of the CelRH5 protein, bacterial endo- $\beta$-1,4-glucanases were selected as templates by I-TASSER, with the following PDBs, all of which belong to GH5, identified as the top threading templates namely: $3 \mathrm{MMU}, 3 \mathrm{AMD}$, and $3 \mathrm{OAF}$ from Thermotoga maritima; 1CEO from Ruminiclostridium thermocellum; $4 \mathrm{YHE}$ from Bacteroidetes bacterium AC2a together with 3NCO and 3RJY from Fervidobacterium nodosum. All the above cellulases belong to GH5 (Domínguez et al., 1996; Pereira et al., 2010; Wu et al., 2011; Zheng et al., 2012; Naas et al., 2015). A 3D model with TM-score of $0.73 \pm 0.11$ and C-score of 0.13 [the endoglucanase TmCel5A (PDB 3MMU) of Thermotoga maritima] was obtained from the first modeling round and was the best template. I-TASSER also identified the closest structural analogs in PDB (Table 2), all belonging to GH family 5 . The TM-align values revealed that CelRH5 shows a high similarity with members of the GH5 family. Given that 3MMU was the best template found by I-TASSER and that 3RJX and 3MMU were found to be the two closest structural analogs in PDB, three additional modeling rounds using these PDBs were conducted in order to obtain a more accurate 3D model for CelRH5. The best 3D model was obtained using PDB 3MMU as a template with TM-score of $0.89 \pm 0.09$ and C-score of 0.58 (Figures 3A,B). The 3D model showed the common $(\beta / \alpha)_{8}$ TIM-barrel fold present in GH5 family members (Henrissat et al., 1995). In these modeling rounds, I-TASSER also identified endoglucanases belonging to GH family 5 as the closest structural neighbors for CelRH5. The topology of CelRH5 was found to be similar to the topology of PDB 3MMU (Figures $4 \mathbf{A}, \mathbf{B}$ ). In addition to the eight $\alpha$-helices involved in the TIM-barrel architecture, CelRH5 possessed four additional short $\alpha$-helices: $\alpha 2^{\prime}, \alpha 3^{\prime}, \alpha 6^{\prime}$, and $\alpha 10^{\prime}$ (Figure 4A). On the other hand, the predicted CelRH5's $3 \mathrm{D}$ model revealed two additional $\beta$-strands on the C-terminal end of the protein (Figure 4A). Structural analogs, such as
PDB 3MMU and 3RJY, also share these structural characteristics (Zheng et al., 2012).

A 3D superposition analysis between CelRH5 and some structural neighbors (PDBs 3MMU, 1CEO, 4YHE, 3NCO, and 3RJX) revealed a high structural homogeneity between the proteins (Figure 5A). The main differences in the overlapping proteins were found in the loop regions and not in the TIM-barrel fold. PDBs 3MMU and 3RJX showed the highest structural homogeneity with metric values for structural alignments $\left(\mathrm{Q}_{\mathrm{H}}\right.$-score $)$ of 0.899 and 0.894 , respectively,

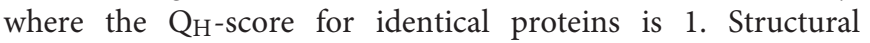
alignments with the $\mathrm{GH}$ analogs identified by I-TASSER allowed conserved residues known to be involved in the hydrolytic mechanism, in positions Glu155 (catalytic acid/base), Glu269 (nucleophile), Arg60, Asn154, His214, and Trp302 (Figure 3B), to be located in CelRH5. Two catalytic glutamates and the histidine which are essential for catalysis displayed the same spatial conformation when PDBs 3MMU, 4YHE, 3RJY, and the CelRH5 model was overlapped (Figure 5B). In CelRH5, the distances between the proton donor Glu155 to His214 and the nucleophile Glu269 to His214 are 6.36 and $5.99 \AA$, respectively (Figure 5C). These distances are higher than in others GH5 such as PDBs 3MMU (Figure 5D), 3RJX (Figure 5E), 4YHE (Figure 5F), CcCel5A and PhCel5G (Zheng et al., 2012).

\section{Cloning, Expression, and Purification of Recombinant celRH5 Cellulase}

In order to biochemically characterize CelRH5, it was necessary to sub-clone the gene and to heterologously express the enzyme in E. coli. To this end the celRH5 gene together with a putative signal sequence was PCR amplified and cloned into the $\mathrm{pBAD} / \mathrm{Myc}$-HisA expression vector under arabinose inducible $\mathrm{pBAD}$ promoter, transformed into E. coli TOP10 cells and the transformants were tested for cellulase activity. The overexpressed His-tagged cellulase 


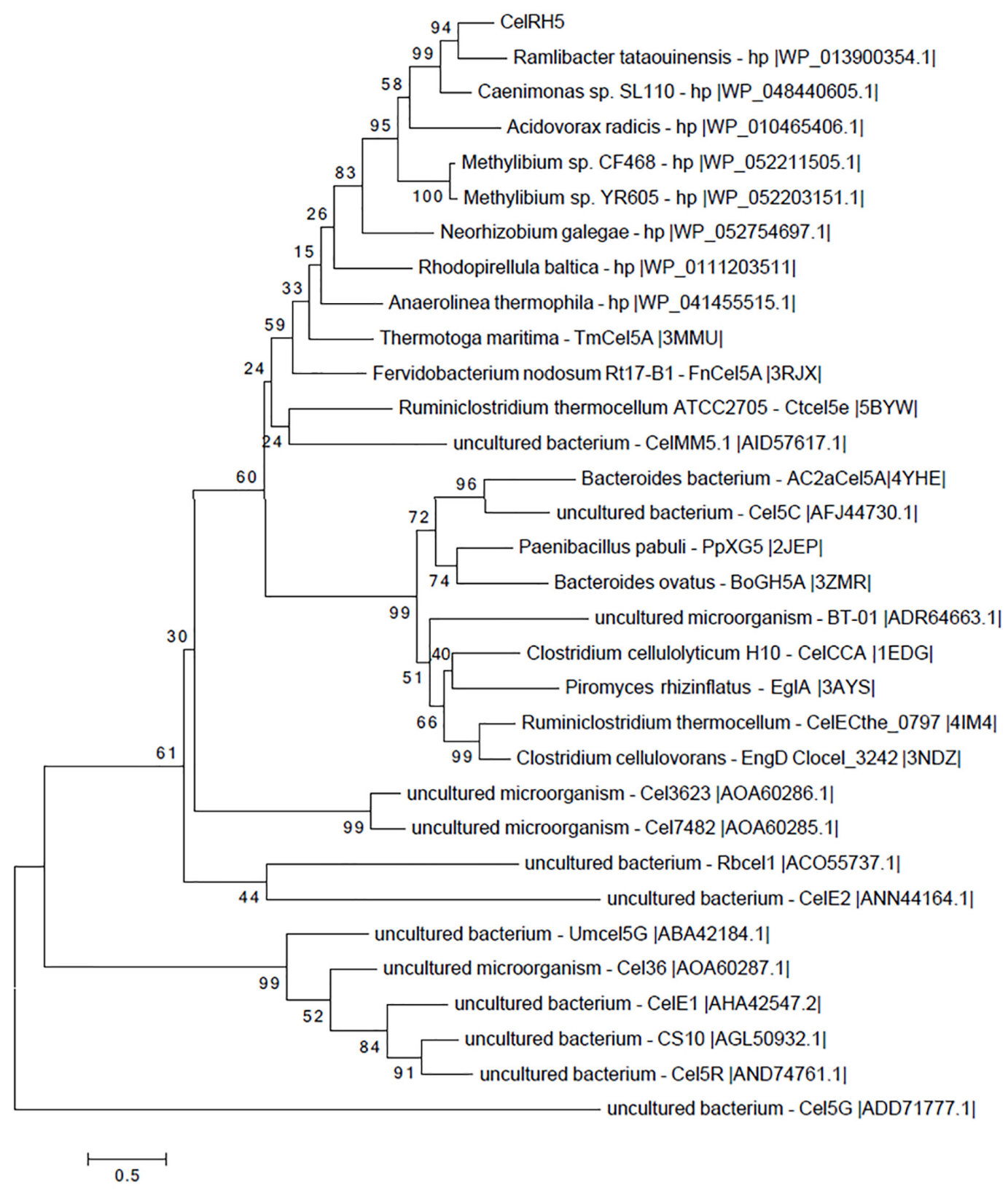

FIGURE 2 | Phylogenetic tree of the CelRH5 amino acid sequence compared to closely related GH5 and other characterized metagenome-derived GH5. Analysis was performed using the MEGA 6.0 application. The tree was constructed using the Maximum Likelihood Method and the LG+G model with bootstrap analysis using 1,000 replicates.

was subsequently purified using the one step nickelimmobilized metal affinity chromatography (Ni-IMAC) method under native conditions resulting in a purification fold of 18.53 (Table 3). The final yield of the recombinant CelRH5 cellulase produced was $3 \mathrm{mg}$ pure protein with a specific activity of $5.56 \mathrm{U} / \mathrm{mg}$ per $1 \mathrm{~L}$ of recombinant E. coli TOP10/pBAD/celRH5 culture. The recombinant enzyme was purified to homogeneity as determined by SDS-PAGE (Figure 6) and the molecular weight of the monomer was estimated to be approximately $40 \mathrm{kDa}$ which corresponding to the expected molecular weight calculated from the CelRH5 amino acid sequence.

\section{Biochemical Characterization of Recombinant Cellulase CeIRH5}

\section{Effect of $\mathrm{pH}$ and Temperature on CelRH5 Activity}

CelRH5 activity was measured in the $\mathrm{pH}$ range $4.0-10.0$. The recombinant enzyme exhibited the highest activity at $\mathrm{pH} 6.5$, displayed almost $80 \%$ of its activity at $\mathrm{pH} 5.5-7.5$ and remained stable at a range of $\mathrm{pH} 4.5-8.5$ after incubation in $30^{\circ} \mathrm{C}$ 
TABLE 2 | Top proteins identified as structural analogs in PDB.

\begin{tabular}{|c|c|c|c|c|c|}
\hline Rank & PDB & TM-score & RMSD & Cov. & Source \\
\hline 1 & 3RJX & 0.927 & 0.89 & 0.942 & Fervidobacterium nodosum \\
\hline 2 & $3 \mathrm{MMU}$ & 0.922 & 0.64 & 0.930 & Thermotoga maritima \\
\hline 3 & 5BYW & 0.911 & 1.26 & 0.936 & Ruminiclostridium thermocellum \\
\hline 4 & $1 \mathrm{EDG}$ & 0.873 & 2.42 & 0.948 & Clostridium cellulolyticum \\
\hline 5 & 4YHE & 0.832 & 2.23 & 0.945 & Bacteroidetes bacterium \\
\hline 6 & $4 \mathrm{XOV}$ & 0.870 & 2.35 & 0.942 & Caldicellulosiruptor sp. \\
\hline 7 & $4 \mathrm{IM} 4$ & 0.869 & 2.04 & 0.927 & Ruminiclostridium thermocellum \\
\hline 8 & 2JEP & 0.868 & 2.04 & 0.930 & Paenibacillus pabuli \\
\hline 9 & $3 N D Z$ & 0.868 & 2.12 & 0.927 & Clostridium cellulovorans \\
\hline
\end{tabular}

Ranking of proteins based on TM-score of the structural alignment between the query structure and known structures in the PDB. RMSD is the distance between residues

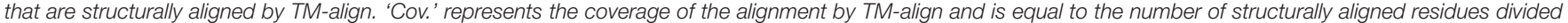
by length of the query protein.

A

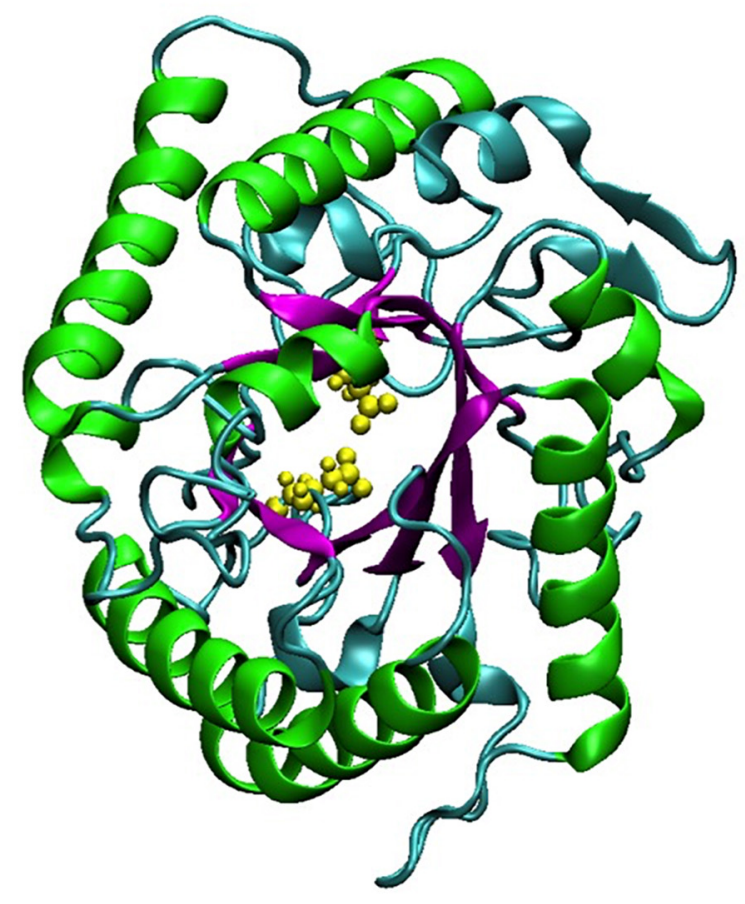

B

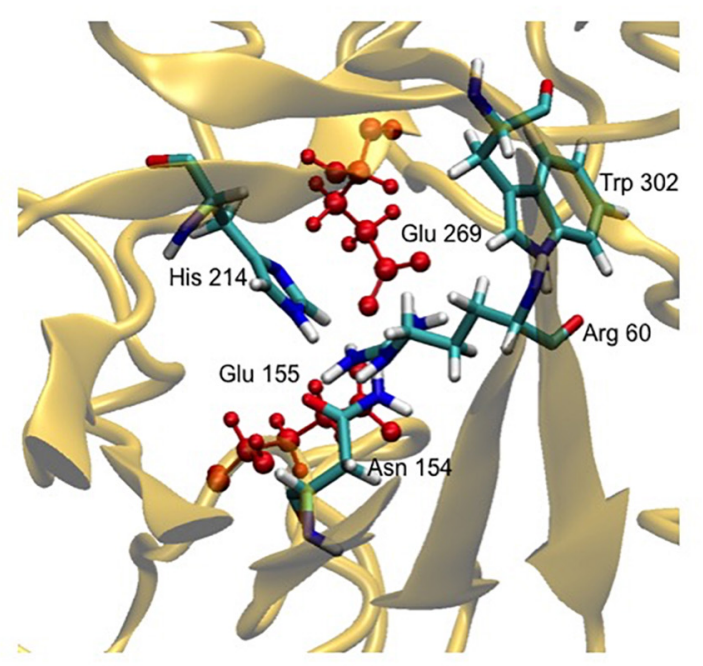

FIGURE 3 | 3D model of CelRH5. (A) TIM-barrel fold $(\beta / \alpha)_{8}$ present in GH5 (magenta and green) and the two catalytic Glu in yellow. (B) Conservative residues involved in catalysis.

for $24 \mathrm{~h}$ (Figure 7). The effect of temperature on CelRH5 activity was assessed in the temperatures range $0-90^{\circ} \mathrm{C}$, with maximum activity being observed at $40^{\circ} \mathrm{C}$, however, CelRH5 was stable up to $30^{\circ} \mathrm{C}$ after $54 \mathrm{~h}$ of incubation but above this temperature the relative activity decreased markedly. After $6 \mathrm{~h}$ of incubation at $40^{\circ} \mathrm{C}$ the enzyme exhibited about $40 \%$ relative activity, however, at $50^{\circ} \mathrm{C}$ after $2 \mathrm{~h}$ the activity was undetectable (Figure 8).

\section{Substrate Specificity of CeIRH5}

The substrate specificity of the CelRH5 was determined in two ways. Initially the recombinant clone $E$. coli TOP10/pBAD/celRH5 was qualitatively assayed on selective media supplemented with various substrates (data not shown). Results obtained from these qualitative screens indicated that the CelRH5 enzyme, when heterologously expressed in E. coli, was active only in the presence of soluble cellulose such as CMC, OBR-HEC and insoluble cellulose AZCL-HEC, with no activity being observed in media supplemented with beechwood xylan, RBB-xylan, AZCL-xylan, avicel or arabic gum. Subsequently the substrate specificity of the purified CelRH5 was quantitatively determined (Table 4). CelRH5 showed activity only with soluble polysaccharides such as CMC and HEC. In turn, no activity with other substrates such as Avicel, beechwood xylan, crab shells, soluble and insoluble chitin, corn stover or $p$-nitrophenol-glucopyranoside 
A

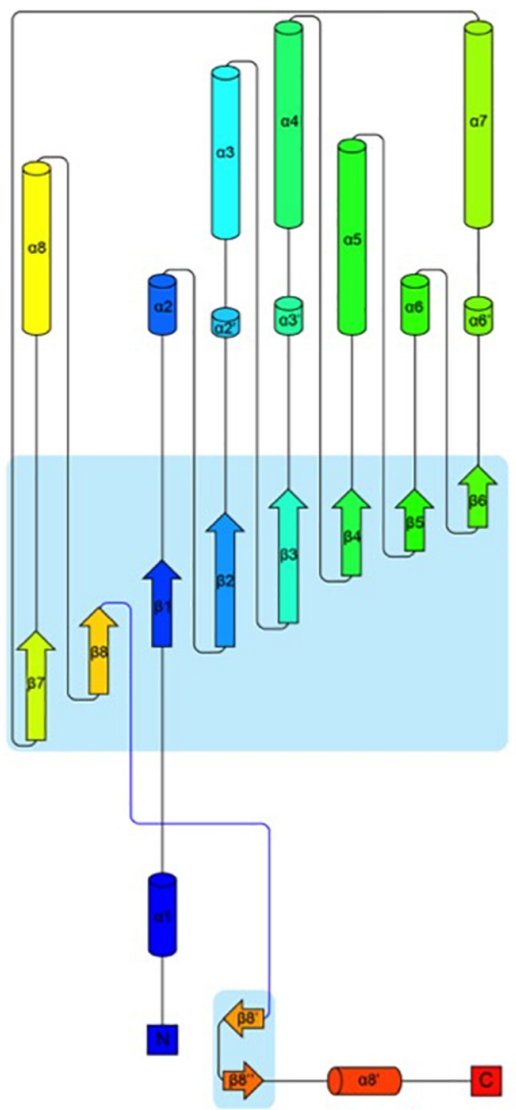

B

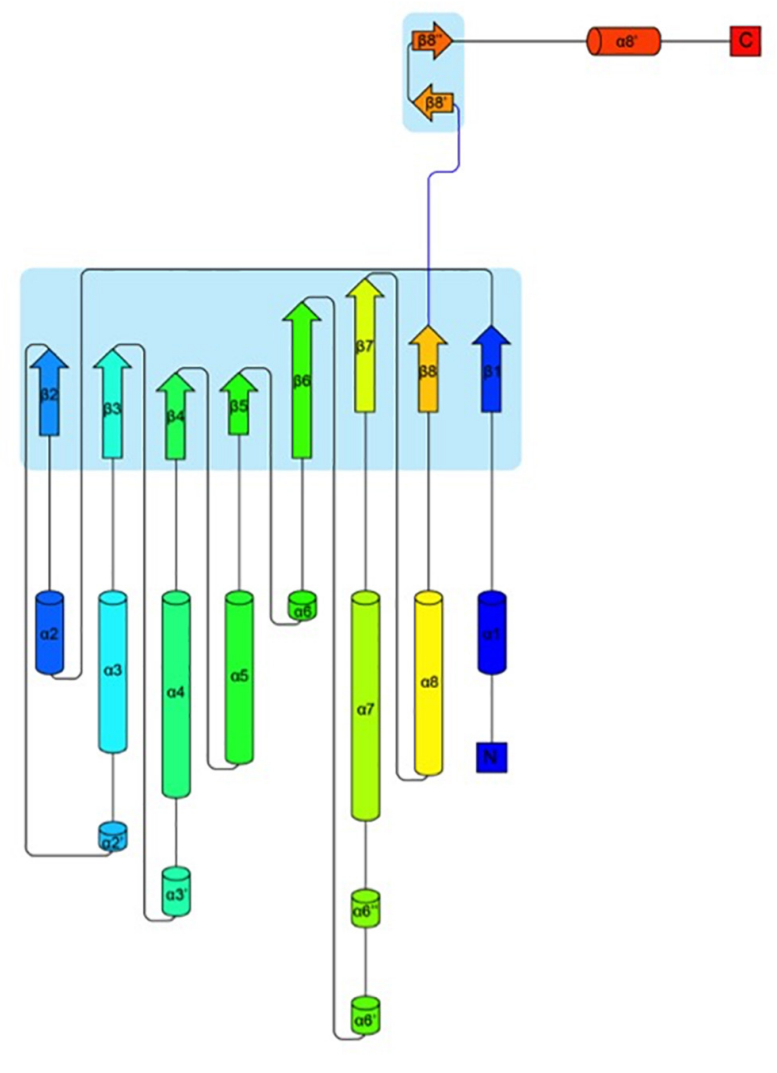

FIGURE 4 | Topology of proteins CeIRH5 (A) and 3MMU (B) showing the architecture of their monomers. The colouring is from blue at the N-terminus to red at the C-terminus. Parts of the chain that have a $\beta$-strand conformation are shown as arrows and $\alpha$-helices are shown as cylinders (Stivala et al., 2011).

( $p$ NPG), $p$-nitrophenol-cellobioside ( $p$ NPC), and $p$-nitrophenolxylopyranoside ( $p$ NPX) was detected.

\section{The Effect of Metal lons and Chemical Reagents on CelRH5 Activity}

The addition of metal ions such as $\mathrm{Na}^{+}, \mathrm{K}^{+} \mathrm{Li}^{+}$, and $\mathrm{Mg}^{2+}$ at concentrations of $1 \mathrm{mM}$ and $10 \mathrm{mM}$ resulted in an increase in cellulase activity even up to $10 \%$ above the maximal activity, however, at higher concentrations addition of $\mathrm{Na}^{+}$and $\mathrm{K}^{+}$ $(100 \mathrm{mM})$ resulted in decreases in enzyme activity to $94 \%$ and $86 \%$, respectively (Figure 9A). Decreases in cellulase activity were also observed upon addition of other metal ions even at low concentrations, with $\mathrm{Zn}^{2+}, \mathrm{Ni}^{2+}, \mathrm{Co}^{2+}$ lowering the relative activity below $20 \%$ and $\mathrm{Fe}^{3+}$ addition resulting in the total inhibition of enzyme activity; while the addition of $10 \mathrm{mM}$ EDTA resulted in only a small decrease in cellulase activity to approximately $98 \%$ of maximal activity. The addition of glucose and cellobiose, final products of cellulose degradation, did not have a marked effect on CelRH5 activity, with the addition of cellobiose at a concentration of $100 \mathrm{mM}$ resulting in a slight decrease in relative activity to $87 \%$ (Figure 9B).

The impact of various other reagents on CelRH5 activity was also assessed (Figure 9C). CelRH5 activity was not affected to any great extent upon addition of denaturing agents such as guanidine- $\mathrm{HCl}$ or urea at concentrations of $0.01 \mathrm{M}$ and $0.1 \mathrm{M}$, however, when the concentration of guanidine- $\mathrm{HCl}$ was increased to $1 \mathrm{M}$ a decrease in relative activity to $15 \%$ was observed. Similarly, the addition of reducing agents such as DTT and 2-ME had no marked effect on cellulase activity, nor did the addition of ethanol at $1 \%(\mathrm{v} / \mathrm{v})$; however, increased ethanol concentrations of $10 \%(\mathrm{v} / \mathrm{v})$ and $20 \%(\mathrm{v} / \mathrm{v})$ resulted in decreases its relative activity of $27 \%$ and $73 \%$, respectively (Figure 9C). The addition of DMSO also resulted in slight reductions in relative activity as did the addition of glycerol at concentration $5 \%(\mathrm{v} / \mathrm{v})$ and $10 \%(\mathrm{v} / \mathrm{v})$. However, of the reagents tested, only the addition of the ionic detergent SDS at concentrations of $0.1 \%(\mathrm{v} / \mathrm{v})$ and $1 \%$ $(\mathrm{v} / \mathrm{v})$ resulted in the complete inactivation of CelRH5 activity.

\section{Kinetic Parameters of the CelRH5 Enzyme}

The kinetic parameters of the metagenome-derived cellulase, CelRH5, were determined in standard conditions $(20 \mathrm{mM}$ sodium phosphate buffer $\mathrm{pH} 6.5,30^{\circ} \mathrm{C}$ ) using various concentrations of OBR-HEC as a substrate. Calculations of the $K_{\mathrm{m}}, V_{\max }$, and $k_{\text {cat }}$ parameters were performed with the GraphPad Prism 7.02 application based on Michaelis-Menten model. The $K_{\mathrm{m}}$ was $0.675 \mathrm{mg} / \mathrm{mL}$, while the $V_{\max }$ and $k_{\text {cat }}$ 
A

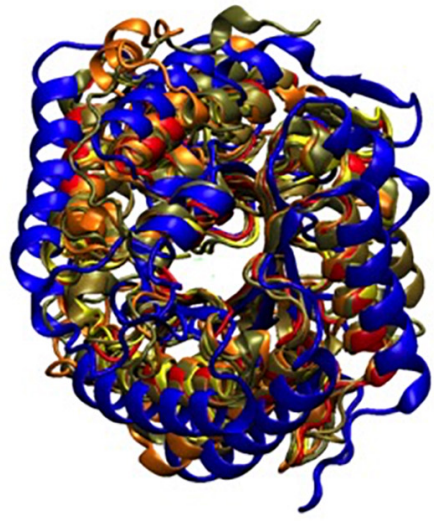

D

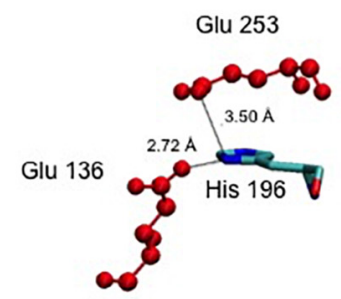

B

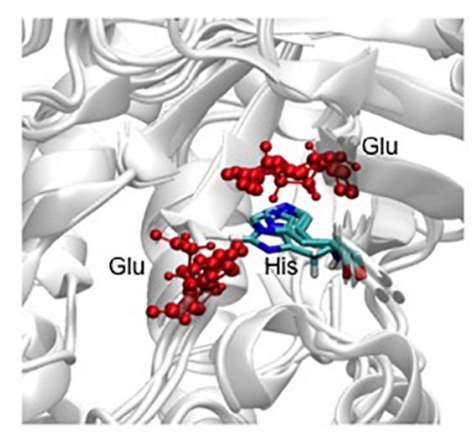

E

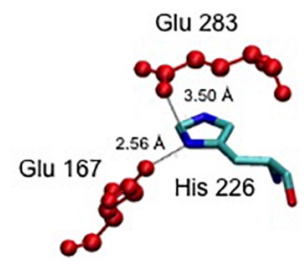

C

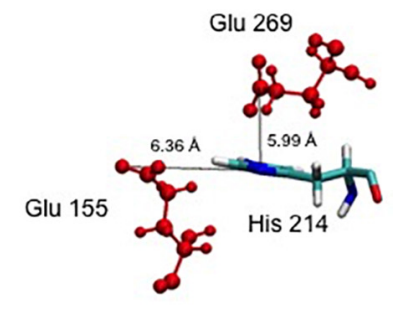

$\mathbf{F}$

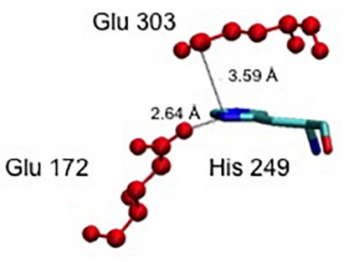

FIGURE 5 | (A) The 3D superposition between CelRH5 and some structural neighbors. (B) The catalytic Glu and His 3D superposition between CelRH5 and some structural neighbors. (C-F) Evidence for the distance between the two catalytic Glu and His involved in the active center in CelRH5 and some structural neighbors $3 \mathrm{MMU}$ (D), 3RXY (E) and 4YHE (F).

TABLE 3 | Summary of purification of CelRH5 cellulase from $150 \mathrm{~mL}$ of $E$. coli TOP10/pBAD/celRH5 culture.

\begin{tabular}{lcccc}
\hline Purification step & $\begin{array}{c}\text { Total protein } \\
(\mathbf{m g})\end{array}$ & $\begin{array}{c}\text { Total } \\
\text { activity (U) }\end{array}$ & $\begin{array}{c}\text { Specific activity } \\
\text { (U/mg) }\end{array}$ & $\begin{array}{c}\text { Purification } \\
\text { fold }\end{array}$ \\
\hline Lysate & 18.78 & 5.67 & 0.30 & 1.00 \\
Ni-IMAC & 0.45 & 2.50 & 5.56 & 18.53 \\
\hline
\end{tabular}

Activity was performed using standard assay with OBR-HEC as a substrate. Protein determination was performed with Bradford method.

parameters were calculated as $14.27 \mu \mathrm{mol} . \mathrm{min}^{-1}$ per $\mathrm{mg}$ of protein and $9.75 \mathrm{~s}^{-1}$, respectively.

\section{DISCUSSION}

Function-based metagenomics involving the heterologous expression of environmental DNA without the need for culture isolation or sequence based analyses has led to the identification of numerous enzymes in metagenomic clone libraries (Nacke et al., 2012; Jackson et al., 2015; Borchert et al., 2017). Because of their industrial utility much interest has focused on the functional screening of metagenomics libraries for novel cellulases. A number of metagenome derived cellulases have been reported to date, from a variety of sources including animal rumens (Cheng et al., 2016); insects and nematodes feeding on cellulose (Zhang et al., 2013; Lee et al., 2014), and from a variety of other environments (Alvarez et al., 2013; Martin et al., 2014; Meneses et al., 2016; Yang et al., 2016), including soil (Berlemont et al., 2009; Zhou et al., 2016; Pimentel et al., 2017). Moreover, analyses based on metagenomic sequences revealed that soils are rich in glycosyl hydrolases which decompose plant polysaccharides including cellulose (Berlemont and Martiny, 2016). Here the functional screening of a rhizosphere-derived metagenomic clone library led to the identification of the celRH5 gene with endoglucanase activity. Phylogenetic analysis indicated that the nucleotide sequence of the 1,080 bp celRH5 gene was related to a putative endo-1,4-glucanase from Ramlibacter tataouinensis spp. showing 66-68\% identity (Figure 2). BLASTp analysis of the deduced amino acid sequence indicated that CelRH5 exhibited the highest homology with hypothetical proteins from Caenimonas sp. SL110 and Ramlibacter tataouinensis spp. showing $66 \%$ and $68 \%$ of identity, respectively; with identity to other putative proteins being below $60 \%$. With respect to previously characterized homologs of CelRH5 the highest identity was observed with thermostable cellulases TmCel5A from Thermotoga maritima, (Chhabra et al., 2002); FnCel5A from Flavidobacterium nodosum Rt17B1 (Wang et al., 2010) and Ctcel5e from Ruminiclostridium thermocellum ATCC 27405 (Yuan et al., 2015) with CelRH5 sharing 39\%, 36\%, and 34\% 


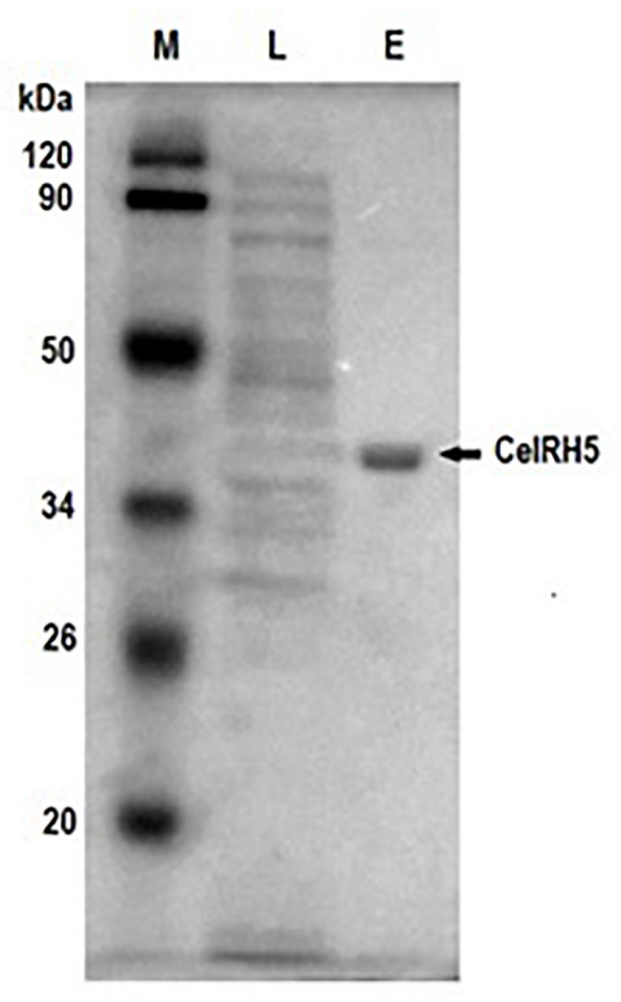

FIGURE 6 | SDS-PAGE of the recombinant cellulase CelRH5 during purification steps. Lane M contains the protein molecular weight markers, lane $L$ is the lysate from the $E$. coli TOP10/CelRH5 cells after protein overexpression, lane $\mathrm{E}$ is the recombinant enzyme CelRH5 eluted following the purification step with the His-tag Ni-NTA Resin.

identity, respectively, with those enzymes. The sequence identity between the deduced amino acid sequence of CelRH5 and other cellulase sequences in the databases are less than $70 \%$, indicating that our celRH5 gene is novel.

Bioinformatic analysis revealed that CelRH5 appears to possess one full catalytic domain composed of 268 aa typical of GH5, together with an N-terminal signal peptide composed of 31 aa. Moreover, the in silico generated 3D model indicated that CelRH5 exhibited the highest structural homology to other endo- $\beta$-1,4-glucanases from the GH5 family. Thus both the sequence analysis and the structural similarity suggest that CelRH5 belongs to the GH5 with endo- $\beta$-1,4-endoglucanase activity. GH5 (formerly known as "cellulase family A") is one of the largest families of all glycosyl hydrolases (Aspeborg et al., 2012; Lombard et al., 2014). In general, GHs use acid-base catalysis to cleave glycosidic bonds with the hydrolytic mechanism in GH5 involving two strictly conserved glutamate residues; the catalytic acid/base and the nucleophile (Henrissat et al., 1995). In addition, a conserved histidine residue (His226 in PDB 3RJX) located in the substrate-binding site has been shown to be relevant for catalysis (Zheng et al., 2012). In addition, four other amino acids (Arg, Asn, His, Trp) located in the substrate-binding pocket are highly conserved in the GH5 family (Hilge et al., 1998). The amino acid and structural alignments using CelRH5 and their structural analog GHs identified by I-TASSER allowed us to locate these residues in CelRH5: Glu155 (catalytic acid/base) and Glu269 (nucleophile); and Arg60, Asn154, His214, and Trp302 (Figures 3, 5A,B). All of these residues were located in the canonical position previously reported in the closest structural neighbors PDBs 3MMU and 3RJX (Pereira et al., 2010; Zheng et al., 2012). The identification of these six strictly conserved residues in GH family 5 members provides additional evidence indicating that CelRH5 is a glycosyl hydrolase and belongs to family 5. Also, bioinformatic analyses revealed the presence of the catalytic triad (Glu-His-Glu) involving two glutamate residues and a histidine residue that are essential for catalytic activity and the same spatial conformation was observed when the CelRH5 model was superimposed on it's nearest structural neighbors, TmCel5A (PDB 3MMU, $A C_{2 a}$ Cel5A (PDB 4YHE) and FnCel5A (PDB 3RJX) (Figure 5B). However, while spatial conformation is important for catalytic efficiency, the distance between the $\mathrm{N} \delta 1$ atom of the imidazole group of histidine and the carboxyl groups of the two catalytic glutamates is also believed to play an important role in catalysis; with distances of $3.5 \AA$ for the hydrogen atoms involved being optimal (Zheng et al., 2012). This structural aspect is interesting since it suggests that some GH5 enzymes may have evolved an electron relay network to facilitate more efficient catalysis (Zheng et al., 2012). However, in CelRH5 the distances between the proton donor Glu155 to His214 and the nucleophile Glu269 to His214 are greater than in other related GH5 members (Zheng et al., 2012), with the distance between Glu155 and Glu269 in CelRH5 being $3.56 \AA$. Thus, based on this CelRH5 may exhibit a lower activity than FnCel5A (PDB 3RJX), TmCel5A (PDB 3MMU), $A C_{2 a}$ Cel5A (PDB 4YHE), CcCel5A and PhCel5G. The distance between Glu155 and Glu269 in CelRH5 is comparable with the distance between equivalent residues in other GH5 members (3.69 $\AA$ in 3RJX and 3.59 $\AA$ in 3MMU). Regardless, GH5 is one of the largest and well characterized GH families, and constitutes a group of monospecific enzymes as well as enzymes that demonstrate a large variety of specificities. Currently GH5 exemplifies a family which contains over 20 experimentally determined enzyme activities denoted with an EC number including endoglucanase, $\beta$-mannanase, exo-1,3-glucanase, endo-1,6-glucanase, xylanase and many others (Aspeborg et al., 2012; Lombard et al., 2014). With this in mind, biochemical assays were performed to further characterize the purified CelRH5 enzyme.

While functional metagenomics is a very promising approach in the isolation and identification of novel gene variants, problems can be encountered with expression in heterologous hosts; particularly with respect to the formation of inclusion bodies (Kennedy et al., 2008; Lambertz et al., 2014) Although our recombinant celRH5 gene construct which we had cloned into the arabinose inducible expression vector $\mathrm{pBAD} / \mathrm{Myc}$ HisA contained a signal sequence and while activity was observed, high levels of the recombinant CelRH5 enzyme were present within the $E$. coli TOP10 cells indicating the likelihood of inclusion bodies being formed. We overcame this problem by inducing protein expression at the lower temperature of $20^{\circ} \mathrm{C}$ for a short 3 -h time period, during which 
A

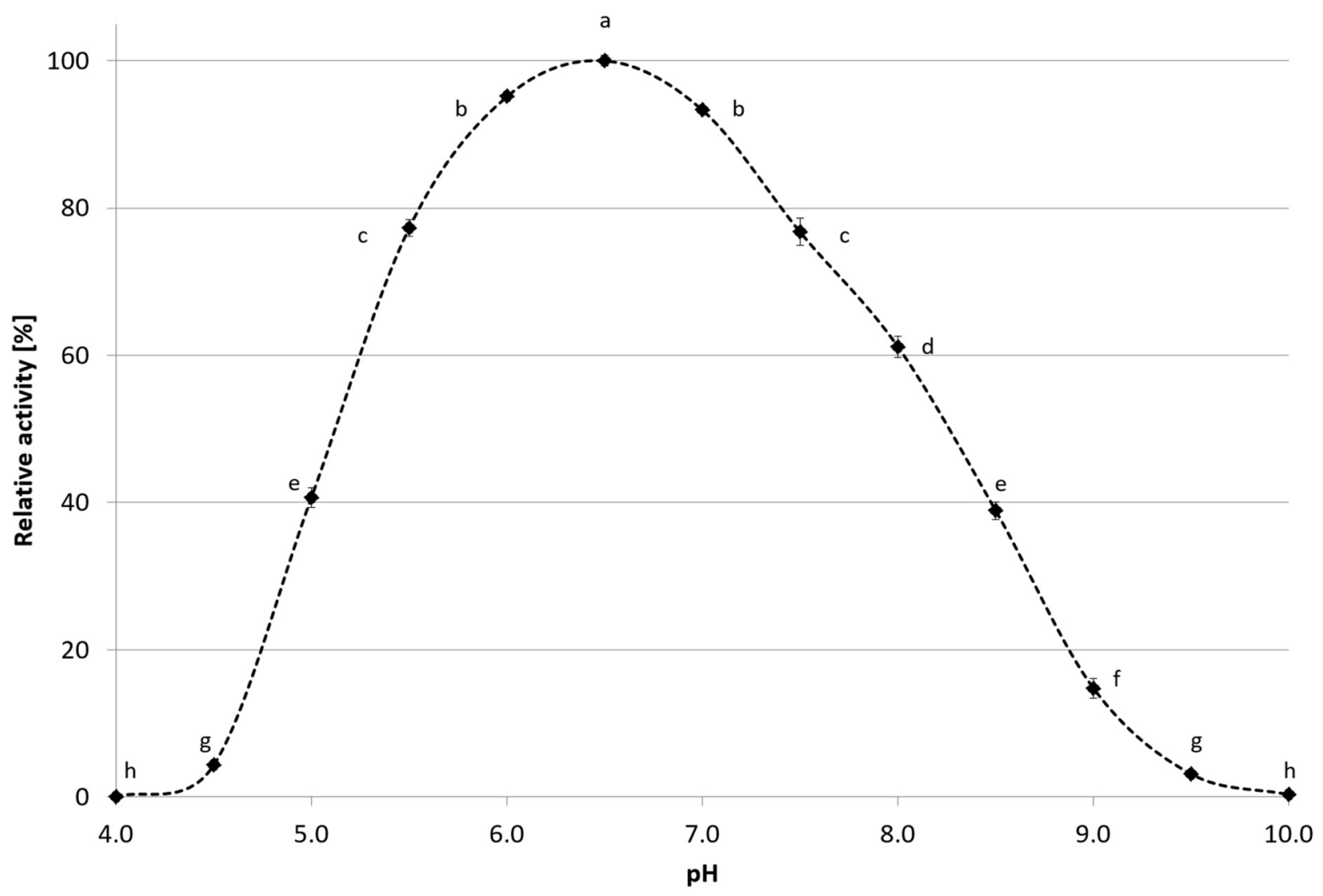

B

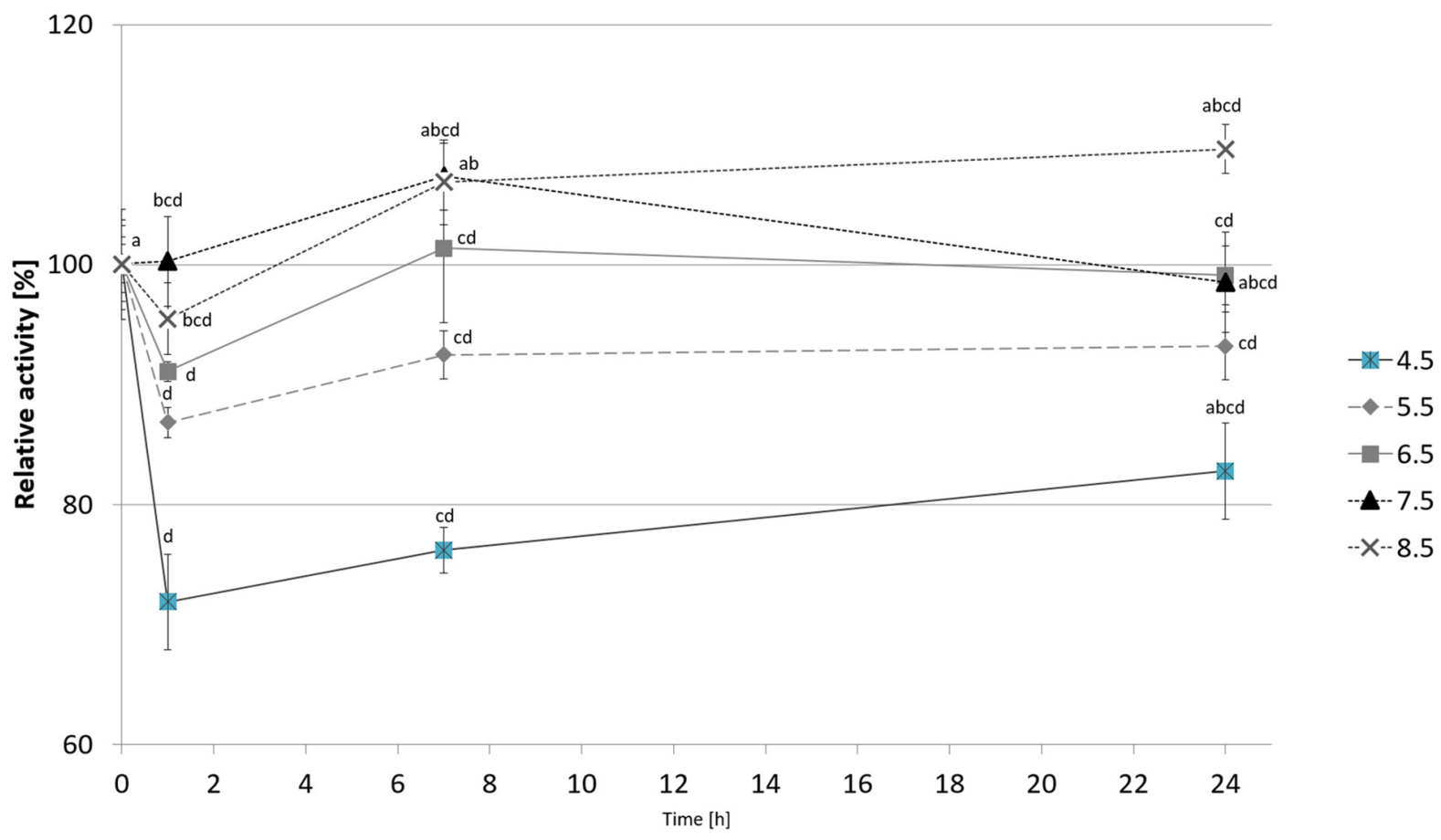

FIGURE 7 | The effect of $\mathrm{pH}$ on recombinant CelRH5 activity (A) and stability (B). Activity toward OBR-HEC was determined at 20 mM Britton-Robinson buffer at $20^{\circ} \mathrm{C}$. The error bars represent the standard deviation $(n=3)$ and different letters mean statistically significant differences. 
A

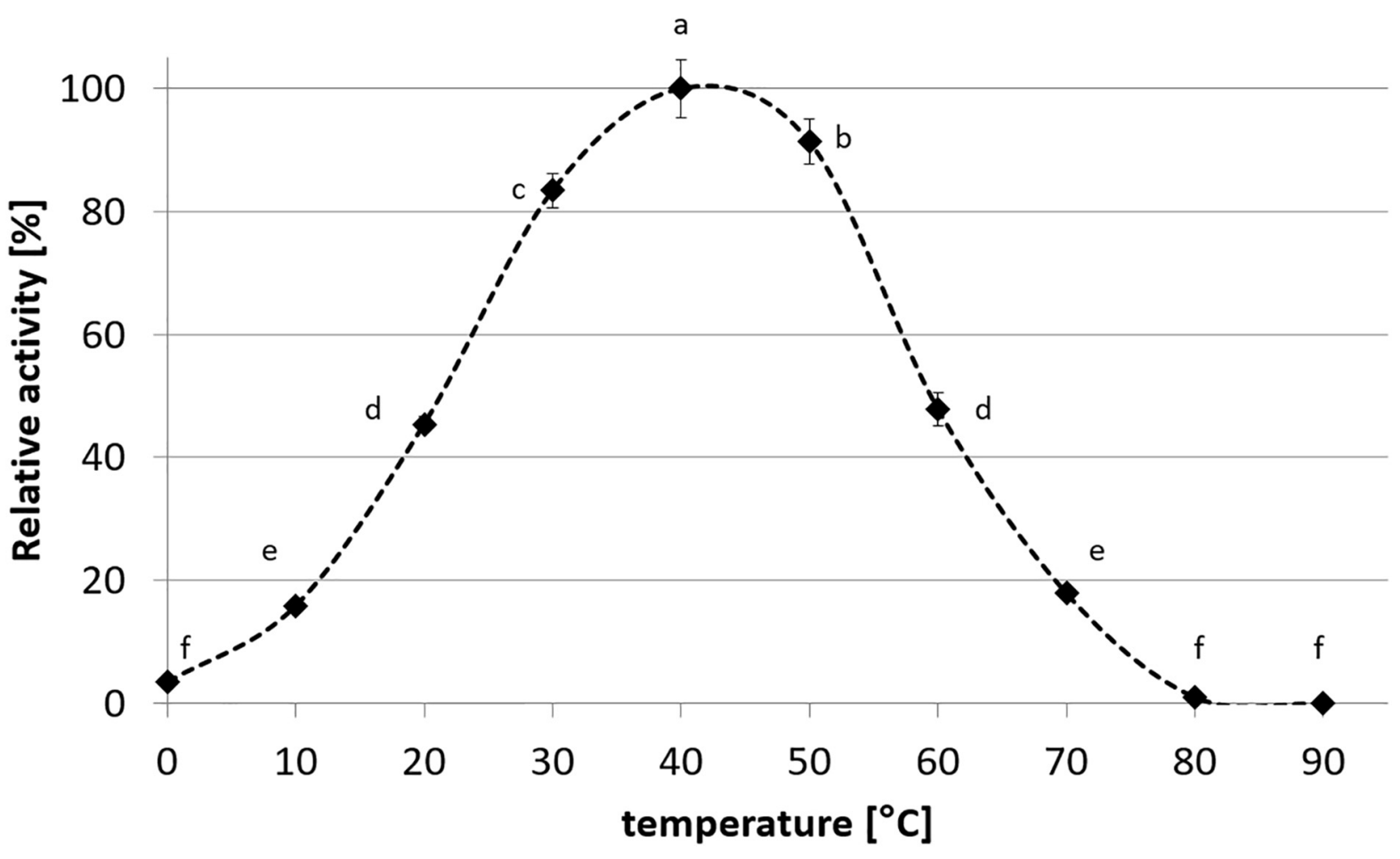

B

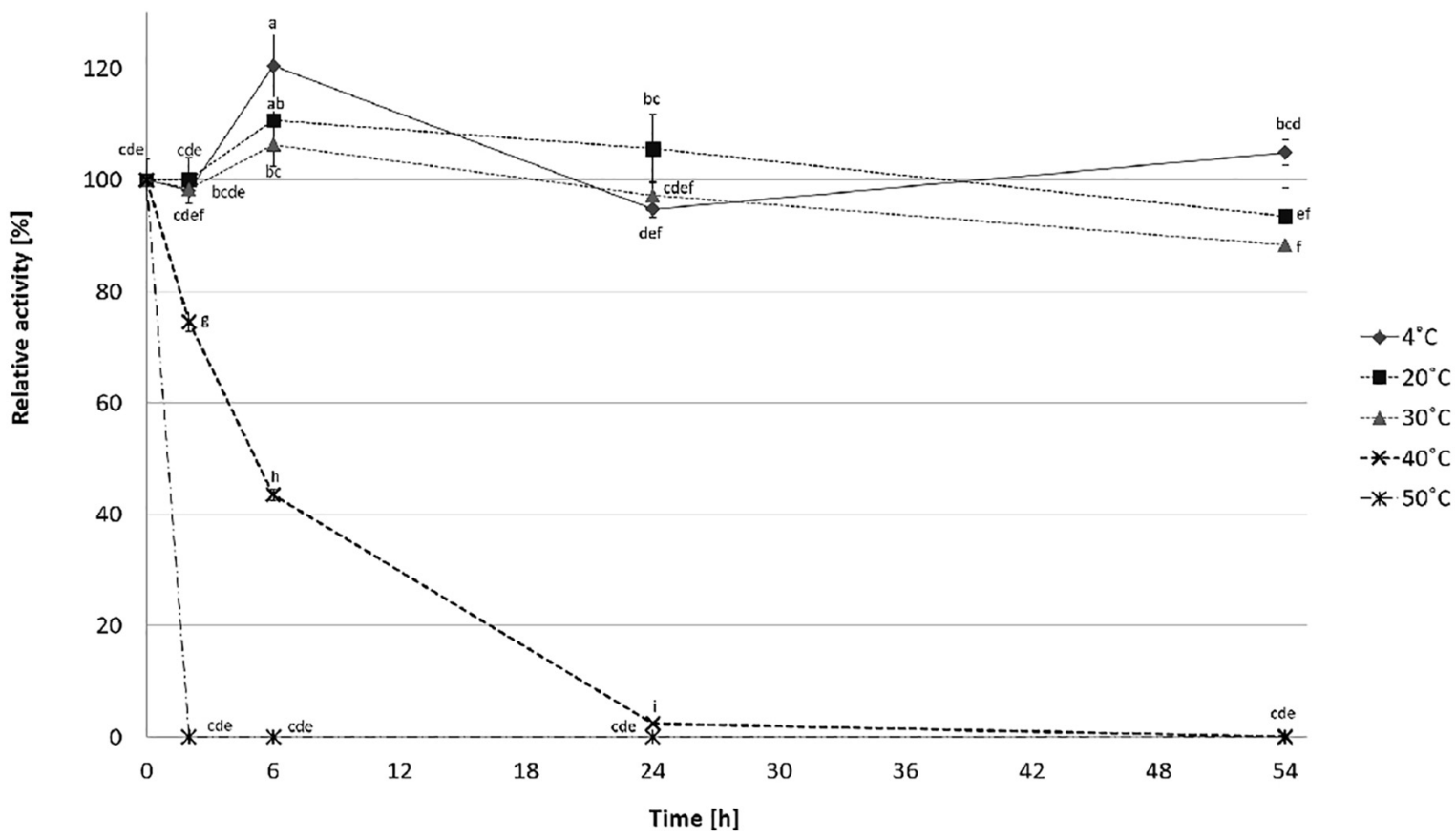

FIGURE 8 | The effect of temperature on recombinant CelRH5 activity (A) and stability (B). Activity toward OBR-HEC was determined at 20 mM sodium phosphate buffer $\mathrm{pH}$ 6.5. The error bars represent the standard deviation $(n=3)$ and different letters mean statistically significant differences.

time the culture was shaking with a spiral coil placed in the medium which allowed additional aeration. This allowed the one step purification of the soluble CelRH5 enzyme using the Ni-IMAC method with a purification yield of $44 \%$
(Table 3 and Figure 6). The specific activity with OBR-HEC as substrate increased from $0.3 \mathrm{U} / \mathrm{mg}$ in the crude cell lysate to $5.56 \mathrm{U} / \mathrm{mg}$ after Ni-NTA affinity chromatography, which is an 18-fold purification of the recombinant enzyme; allowing 
TABLE 4 | Substrate specificity of recombinant CelRH5.

\begin{tabular}{lc}
\hline Substrate & CelRH5 (U/mg) \\
\hline CMC & $1,58 \pm 0,03^{\mathrm{a}}$ \\
HEC & $0,65 \pm 0,05^{\mathrm{a}}$ \\
Avicel & $0^{\mathrm{a}}$ \\
Beech wood xylan & $0^{\mathrm{a}}$ \\
Crab shells chitin (soluble) & $0^{\mathrm{a}}$ \\
Crab shells chitin (insoluble) & $0^{\mathrm{a}}$ \\
Corn stover & $0^{\mathrm{a}}$ \\
$p-N P G$ & $0^{\mathrm{b}}$ \\
$p-N P C$ & $0^{\mathrm{b}}$ \\
$p-N P X$ & $0^{\mathrm{b}}$
\end{tabular}

Specific activity was determined in optimal conditions for CelRH5 using aMiller's method or by quantification of released $p$-NP from chromogenic substrate; values represent the specific activity \pm standard deviation $(n=3)$.

$3 \mathrm{mg}$ of purified CelRH5 enzyme to be obtained from a $1 \mathrm{~L}$ culture of E. coli.

We subsequently biochemically characterized the recombinant CelRH5 enzyme investigating the influence of temperature, $\mathrm{pH}$, metal ions and chemical reagents on enzyme activity, together with substrate specificity. OBR-HEC was used as a substrate as it proved to be sensitive and stable under the different assay conditions. With respect to the influence of $\mathrm{pH}$, CelRH5 shows approximately $80 \%$ of relative activity within the $\mathrm{pH}$ range between 5.5 and 7.5 with the highest activity at $\mathrm{pH} 6.5$ (Figure 7). The enzyme also displayed good tolerance to a broad $\mathrm{pH}$ range (4.5-8.5), retaining a residual activity above $80 \%$ after $24 \mathrm{~h}$ of incubation at $30^{\circ} \mathrm{C}$. Thus the endoglucanase CelRH5 is more active in slightly acidic conditions but is also quite active and stable under slightly alkaline conditions. While a number of other metagenome-derived endoglucanases from GH5 have also shown highest activity in $\mathrm{pH}$ range 4.5-7.0 (Feng et al., 2007; Alvarez et al., 2013; Martin et al., 2014; Lin et al., 2016), there are fewer examples of endoglucanases exhibiting activity over such a broad pH range (Lee et al., 2014; Garg et al., 2016; Lin et al., 2016).

CelRH5 has a temperature optimum of $40^{\circ} \mathrm{C}$ (Figure 8A). Thermostability experiments which involved incubating the enzyme at different temperatures for up to $54 \mathrm{~h}$ determined that CelRH5 is stable at temperatures up to $30^{\circ} \mathrm{C}$. Incubation at higher temperatures such as $40^{\circ} \mathrm{C}$ for $2 \mathrm{~h}, 6 \mathrm{~h}$, and $24 \mathrm{~h}$ decreased the relative activity to $73 \%, 42 \%$, and $2 \%$, respectively, while at $50^{\circ} \mathrm{C}$ the enzyme was inactive after $2 \mathrm{~h}$ (Figure 8B). Nonetheless CelRH5 is also active and stable at lower temperatures displaying $16 \%$ and $45 \%$ relative activity at $10^{\circ} \mathrm{C}$ and $20^{\circ} \mathrm{C}$, respectively. However, despite the fact that bioinformatic analysis revealed that CelRH5 is most similar to the thermostable cellulases TmCel5A and FnCel5A with optimal temperature of approximately $80^{\circ} \mathrm{C}$, and with Ctcel5e with an optimal temperature of $50^{\circ} \mathrm{C}$; CelRH5 possesses thermal properties that are more typical of enzymes derived from psychrophilic microorganisms (Pereira et al., 2010; Wang et al., 2010). This property distinguishes CelRH5 from other previously characterized soil metagenome-derived GH5 cellulases (Voget et al., 2006; Alvarez et al., 2013; Garg et al., 2016; Pimentel et al., 2017), which exhibited activity and stability at higher temperatures even though they were isolated from metagenomic libraries of mesophilic or psychrophilic origin; with optimal activities between 40 and $55^{\circ} \mathrm{C}$ and stability ranging from $40^{\circ} \mathrm{C}$ and $60^{\circ} \mathrm{C}$ (Voget et al., 2006; Berlemont et al., 2009; Liu et al., 2010; Nacke et al., 2012). CelRH5 is similar biochemically with respect to $\mathrm{pH}$ and temperature optima to a halotolerant cold active marine GH5 endoglucanase, CelMM5 derived from the metagenome of the brown alga Ascophyllum nodosum. This enzyme also possesses a broad range of $\mathrm{pH}$ stability between 4.0 and 10.0 with highest activity at $\mathrm{pH} 7.0$ and exhibits highest activity at $40^{\circ} \mathrm{C}$, but is also stable up to $30^{\circ} \mathrm{C}$ (Martin et al., 2014).

The effects of various metal ions and reagents on CelRH5 activity was assessed with different effects being observed in the presence of various metal ions. $\mathrm{Na}^{+}, \mathrm{K}^{+}, \mathrm{Li}^{+}$, and $\mathrm{Mg}^{2+}$ at concentrations up to $10 \mathrm{mM}$ resulted in slight increases in activity of up to $10 \%$, whereas the addition of $\mathrm{Zn}^{2+}, \mathrm{Ni}^{2+}, \mathrm{Co}^{2+}$, and $\mathrm{Fe}^{3+}$ ions at the same concentrations resulted in decreases in relative activity to below 20\% (Figure 9A). In addition when the chelating agent EDTA at $10 \mathrm{mM}$ was added CelRH5 retained 98\% of the relative activity. Similar results were obtained for cellulase C67-1 derived from buffalo rumen, belonging to the GH5 family, where EDTA had no impact on the enzyme activity, whereas ions of $\mathrm{Zn}^{2+}, \mathrm{Cu}^{2+}, \mathrm{Cr}^{2+}, \mathrm{Mn}^{2+}, \mathrm{Co}^{2+}$, and $\mathrm{Fe}^{2+}$ decreased its relative activity (Duan et al., 2009). These results suggest that CelRH5 is not a metallo-enzyme and its catalytic activity is not dependent on metal ions. In general CelRH5 appears to be quite a stable enzyme with no marked reduction in it's activity being observed upon addition of a number of different reagents including reducing agents such as DTT and 2-ME, urea, guanidine- $\mathrm{HCl}$ (below 0.1 M), DMSO or glycerol (Figure 9C). Major reductions in the relative activity of CelRH5 were only observed upon addition of $1 \mathrm{M}$ guanidine- $\mathrm{HCl}$ and ethanol at either 10 or $20 \%$. In addition, the anionic detergent SDS completely inactivated CelRH5 even at low concentrations $0.1 \%$ (v/v) (Figure 9C), which has previously also been reported for other GH5 family cellulases (Lee et al., 2014; Martin et al., 2014; Garg et al., 2016; Lin et al., 2016; Pimentel et al., 2017). CelRH5 does not appear to be repressed by either cellobiose or by glucose which are the major end products of cellulose degradation, where at $100 \mathrm{mM}$ concentrations only slight decreases in activity to $87 \%$ and 93\%, respectively, were observed (Figure 9B). It is well established that the accumulation of glucose and cellobiose, the end products of hydrolysis, typically inhibit cellulases and decrease overall glucose yields (Hsieh et al., 2014). This substrate inhibition phenomenon is known as the "high solids effect" and negatively impacts on cellulose hydrolysis on an industrial scale and consequently on the commercial aspects of bioethanol production (Cannella and Jorgensen, 2014). Thus given the lack of inhibition observed in the presence of cellobiose and glucose then CelRH5 may be a useful enzyme to use in cellulase enzyme cocktails for bioethanol production.

Enzymes from GH5 family typically represent both monospecific and multi-specific enzymes which exhibit a range of diverse activities, including amongst others endo- $\beta$-1,4-glucanase, endo- $\beta$-1,4-xylanase, $\beta$-glucosidase, chitosanase, $\beta$-mannosidase activities (Aspeborg et al., 2012; Lombard et al., 2014). While the specificity of CelRH5 was 


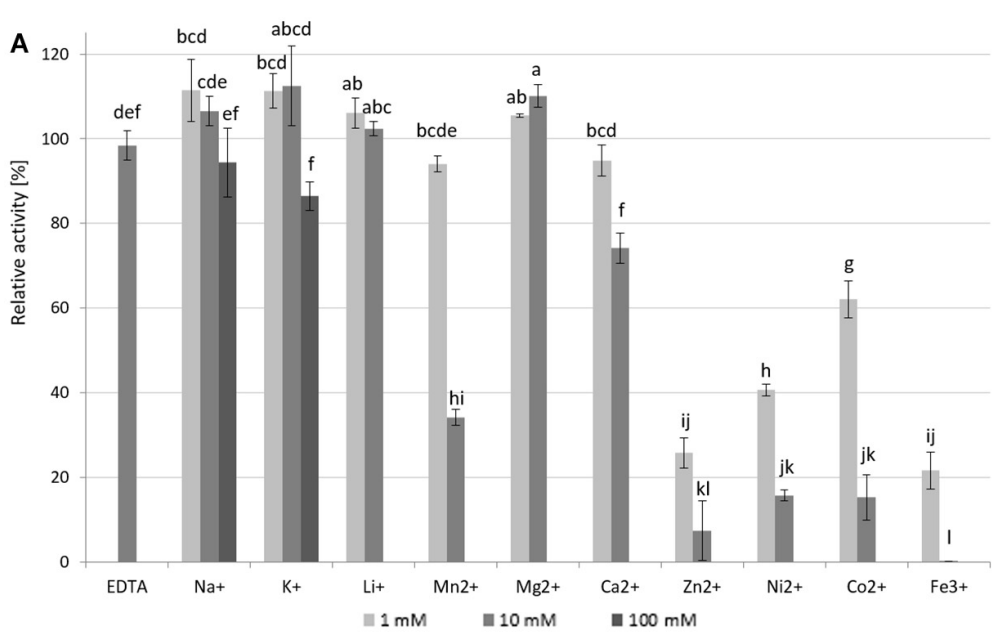

\section{B}

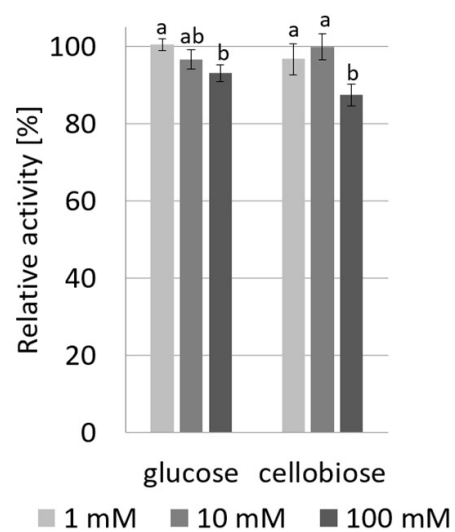

C

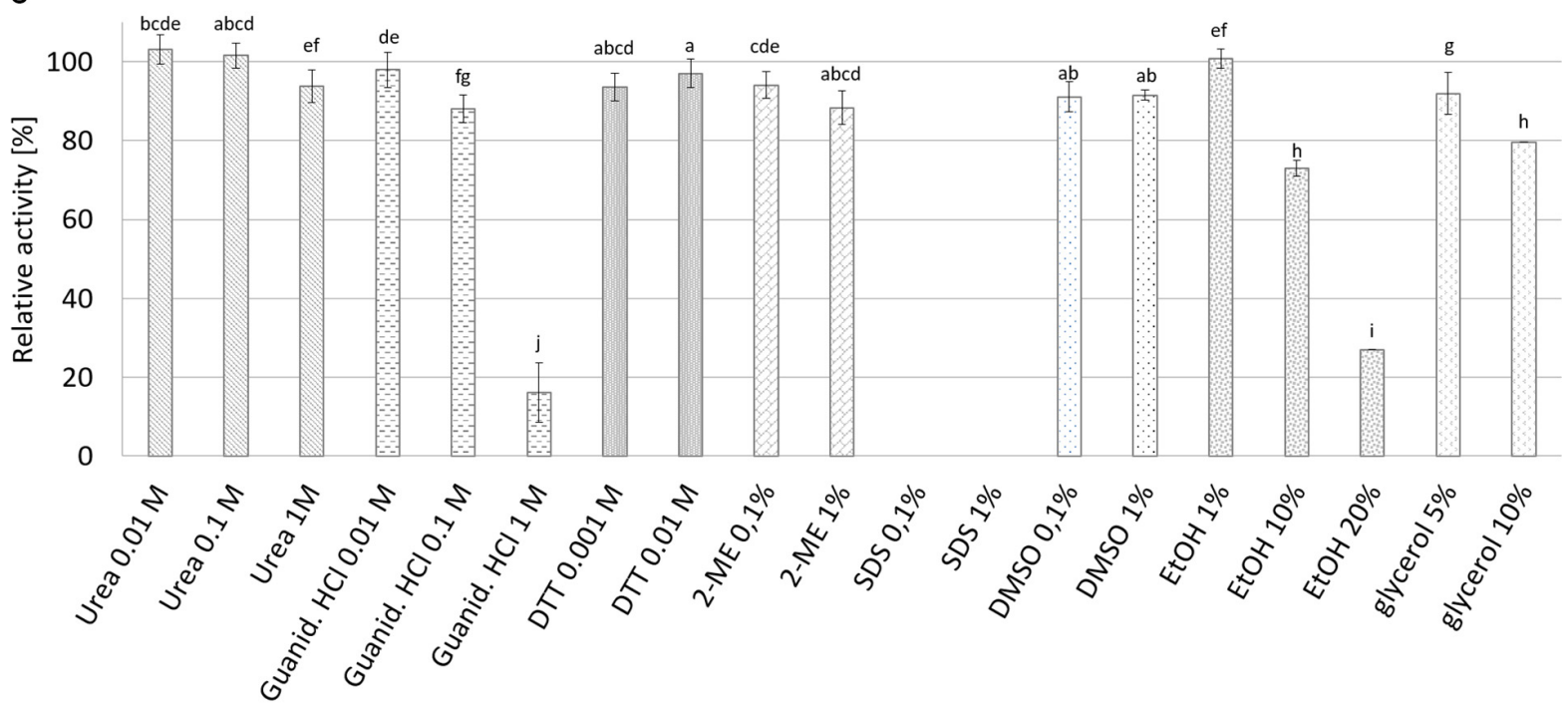

FIGURE 9 | The effect of metals, sugars and various chemical agents on recombinant CeIRH5 activity. (A) Influence of EDTA and metal ions on the CelRH5 activity. (B) Influence of glucose and cellobiose on the CelRH5 activity. (C) Influence of selected reagents on the CelRH5 activity. Control activity is sample without addition of reagents representing 100\%. The error bars represent the standard deviation $(n=3)$ and different letters mean statistically significant differences.

examined with a broad range of substrates (Table 4) activity was only observed with CMC and hydroxyethylcellulose (HEC), with no activity being detected with Avicel, the crystalline form of cellulose. These substrates mainly contain $\beta$-1,4-glycosidic bonds but differ in solubility. The CelRH5 enzyme was also not active against aryl-glycosidic substrates such as $p$ NPC, $p N P G$, and $p$ NPX indicating that CelRH5 is a monospecific endo- $\beta$-1,4-glucanase that acts on internal $O$-glycosidic bonds in soluble homo-polysaccharides composed of glucose units. This is supported by our in silico structural analysis of the predicted CelRH5 3D model which strongly indicates that this enzyme should be classified as a new protein which belongs to GH5 family with endo- $\beta$-1,4-glucanase activity. The lack of CelRH5 activity toward an insoluble form of cellulose might be due to the apparent absence of a cellulose-binding module (CBM) in the enzyme's predicted structure (Mahadevan et al., 2008; Wang et al., 2010, 2012; Reyes-Ortiz et al., 2013; Lee et al., 2014; Zhou et al., 2016), which was shown for other cellulases from the GH5 family, resulting in the ability to only degrade the amorphous form of cellulose (Voget et al., 2006; Mahadevan et al., 2008; Lee et al., 2014). The cellulases TmCel5A from Thermotoga maritima and FnCel5A from Fervidobacterium nodosum, which are the most related homologs of CelRH5, also contain only one catalytic GH5 family domain and while they display a spectrum of activity toward various substrates (Chhabra et al., 2002; Wang et al., 2010) they are not active against Avicel. TmCel5A has, however, been domain engineered, involving addition of a CBM domain to increase its activity toward Avicel by between 12- and 18-fold (Mahadevan et al., 2008). A similar CBM domain engineering approach with FnCel5A had 
a similar effect on the enzyme's activity toward Avicel (Wang et al., 2012). Thus, affinity for the various forms of cellulose, amorphous and crystalline, may be related to the presence of additional CBMs covalently attached to the enzyme. It has been previously shown that many carbohydrate glycoside hydrolases contain additional CBMs in their structures that affect the ability to bind to insoluble substrates (Horn et al., 2012; Pakarinen et al., 2014). Such natural cellulolytic systems often combine several endo- and exo-acting enzymes with various preferences to different forms of the substrate. Their co-operation leads to the decomposition of crystalline and amorphous cellulose with glucose monomers being released (Pérez et al., 2002; Sukumaran et al., 2005; Voget et al., 2006; Fontes and Gilbert, 2010; Kuhad et al., 2011; Blumer-Schuette et al., 2012; Del Pozo et al., 2012; Horn et al., 2012; Lambertz et al., 2014; Pakarinen et al., 2014). Moreover, effective and complete decomposition of polysaccharides such as cellulose involve not only $\mathrm{GH}$ family enzymes but also many others, i.e., polysaccharide lyases, carbohydrate esterases or lytic polysaccharide monooxygenases (LPMOs). In the last 10 years groups of LPMOs, classified as Auxiliary Activity Family 9-11, 13-6, have been described, which generate optimal ends for endoglucanase acting enzymes and are common in bacteria, viruses and fungi (Horn et al., 2012; Lombard et al., 2014; Pakarinen et al., 2014; Filiatrault-Chastel et al., 2019). The endo-acting endoglucanases with LPMOs introduce new reducing or non-reducing chain ends for the exoacting glucanases, which release cellobiose that is converted by $\beta$-glucosidases to glucose. Synergistic actions of these enzymes guarantees the efficient decomposition of lignocellulose biomass.

In summary, our results indicate that CelRH5 is a novel $\beta-1,4-$ endoglucanase belonging to the GH5 family, which is adapted to low temperatures and which has a wide $\mathrm{pH}$ tolerance. The CelRH5 enzyme can be thermally inactivated in a short period of time by increasing the temperature to $50^{\circ} \mathrm{C}$. The enzyme is also active in the presence of final cellulose degradation products, metal ions and various reagents, which are common in many technological processes indicating it's potential suitability for industrial applications. Moreover, cold-adapted enzymes which are used in technological processes allow the use of temperature sensitive substrates and reagents, reducing overall energy consumption and costs. Also, enzymes which are active in low temperatures help to avoid contamination with mesophilic pathogens, which is very important in the food and animal feed industries. In addition, heterologously expressed cellulases, and in particular those that are stable at different $\mathrm{pHs}$ and which are active in presence of various chemicals, are desirable

\section{REFERENCES}

Allgaier, M., Reddy, A., Park, J. I., Ivanova, N., D’haeseleer, P., Lowry, S., et al. (2010). Targeted discovery of glycoside hydrolases from a switchgrassadapted compost community. PLoS One 5:e8812. doi: 10.1371/journal.pone. 0008812

Alvarez, T. M., Paiva, J. H., Ruiz, D. M., Cairo, J. P. L. F., Pereira, I. O., Paixão, D. A. A., et al. (2013). Structure and function of a novel cellulase 5 from sugarcane soil metagenome. PLoS One 8:e83635. doi: 10.1371/journal.pone. 0083635 characteristics for cellulases in the chemical and detergent industries (Gomes and Steiner, 2004; Sukumaran et al., 2005; Li et al., 2009; Kuhad et al., 2011; Vester et al., 2014). It is also worth noting that cellulases which lack the CBM domain, as previously described (Pakarinen et al., 2014), are more easily recovered after hydrolysis and can be reused in subsequent rounds of cellulose processing. Thus, it is clear that CelRH5 may find utility in a variety of different biotechnological applications.

\section{DATA AVAILABILITY}

The sequence of gene celRH5 for these study can be found in GenBank under accession number MK640554.1 (https:// www.ncbi.nlm.nih.gov/nuccore/MK640554.1). The sequence of metagenomic clone RH5_TO-NF021-E23 can be found in the GenBank under accession number MK640553.1 (https://www. ncbi.nlm.nih.gov/nuccore/MK640553).

\section{AUTHOR CONTRIBUTIONS}

AW-W, RH, JK, RB-G, and AD conceived and designed the experiments. AW-W, RH, and LM-Á performed the experiments. AW-W, RH, RB-G, and AD analyzed the data. SJ, JK, and AD contributed to the reagents, materials, and analysis tools. AW-W, RB-G, SJ, and AD wrote the manuscript.

\section{FUNDING}

This project was supported by the FEMS Research Grant (FEMSRG-2014-0007.R1), CONACyT-SEP No. 285816 and Science Foundation Ireland (SSPC-2, 12/RC/2275).

\section{ACKNOWLEDGMENTS}

The authors appreciate very much the collaboration of Axel Ramírez in statistical calculations.

\section{SUPPLEMENTARY MATERIAL}

The Supplementary Material for this article can be found online at: https://www.frontiersin.org/articles/10.3389/fmicb. 2019.01342/full\#supplementary-material

Aspeborg, H., Coutinho, P. M., Wang, Y., Brumer, H., and Henrissat, B. (2012). Evolution, substrate specificity and subfamily classification of glycoside hydrolase family 5 (GH5). BMC Evol. Biol. 12:186. doi: 10.1186/1471-2148-12186

Bashir, Y., Singh, P., and Konwar, B. K. (2014). Metagenomics: an application based perspective. Chin. J. Biol. 2014:146030. doi: 10.1155/2014/146030

Berlemont, R., Delsaute, M., Pipers, D., D’Amico, S., Feller, G., Galleni, M., et al. (2009). Insights into bacterial cellulose biosynthesis by functional metagenomics on Antarctic soil samples. ISME J. 3, 1070-1081. doi: 10.1038/ ismej. 2009.48 
Berlemont, R., and Martiny, A. C. (2016). Glycoside Hydrolases across environmental microbial communities. PLoS Comput. Biol. 12:e1005300. doi: 10.1371/journal.pcbi.1005300

Berman, H. M., Westbrook, J., Feng, Z., Gilliland, G., Bhat, T. N., Weissig, H., et al. (2000). The protein data bank. Nucleic Acids Res. 28, 235-242. doi: 10.1093/nar/ 28.1.235

Biely, P., Mislovièpvã, D., and Toman, D. (1985). Soluble chromogenic substrates for the assay of endo-1,4- $\beta$-xylanases and endo-1,4- $\beta$-glucanases. Anal. Biochem. 144, 142-146. doi: 10.1016/0003-2697(85)90095-8

Blumer-Schuette, S. E., Giannone, R. J., Zurawski, J. V., Ozdemir, I., Ma, Q., Yin, Y., et al. (2012). Caldicellulosiruptor core and pangenomes reveal determinants for noncellulosomal thermophilic deconstruction of plant biomass. J. Bacteriol. 194, 4015-4028. doi: 10.1128/jb.00266-12

Borchert, E., Selvin, J., Kiran, G. S., Jackson, S. A., O'Gara, F., and Dobson, A. D. W. (2017). A novel cold active esterase from a deep sea sponge Stelletta normani metagenomics library. Front. Mar. Sci. 4:287. doi: 10.3389/fmars.2017.00287

Cannella, D., and Jorgensen, H. (2014). Do new cellulolytic enzyme preparations affect the industrial strategies for high solids lignocellulosic ethanol production? Biotechnol. Bioeng. 111, 59-68. doi: 10.1002/bit.25098

Cheng, J., Huang, S., Jiang, H., Zhang, Y., Li, L., Wang, J., et al. (2016). Isolation and characterization of a non-specific endoglucanase from a metagenomic library of goat rumen. World J. Microbiol. Biotechnol. 32:12. doi: 10.1007/s11274-0151957-4

Chhabra, S. R., Shockley, K. R., Ward, D. E., and Kelly, R. M. (2002). Regulation of endo-acting glycosyl hydrolases in the hyperthermophilic bacterium Thermotoga maritima grown on glucan- and mannan-based polysaccharides. Appl. Environ. Microbiol. 68, 545-554. doi: 10.1128/aem.68.2.545-554.2002

De Castro, E., Sigrist, C. J. A., Gattiker, A., Bulliard, V., Langendijk-Genevaux, P. S., Gasteiger, E., et al. (2006). ScanProsite: detection of PROSITE signature matches and ProRule-associated functional and structural residues in proteins. Nucleic Acids Res. 34, W362-W365. doi: 10.1093/nar/gkl124

Del Pozo, M. V., Fernández-Arrojo, L., Gil-Martínez, J., Montesinos, A., Chernikova, T. N., Nechitaylo, T. Y., et al. (2012). Microbial $\beta$-glucosidase from cow rumen metagenome enhance the saccharification of lignocellulose in combination with commercial cellulase cocktail. Biotechnol. Biofuels 5:73. doi: 10.1186/1754-6834-5-73

Domínguez, R., Souchon, H., Lascombe, M., and Alzari, P. M. (1996). The crystal structure of a family 5 endoglucanase mutant in complexed and uncomplexed forms reveals an induced fit activation mechanism. J. Mol. Biol. 257, 1042-1051. doi: 10.1006/jmbi.1996.0222

Duan, C. J., Xian, L., Zhao, G. C., Feng, Y., Pang, H., Bai, X. L., et al. (2009). Isolation and partial characterization of novel genes encoding acidic cellulases from metagenomes of buffalo rumens. J. Appl. Microbiol. 107, 245-256. doi: $10.1111 / \mathrm{j} .1365-2672.2009 .04202 . \mathrm{x}$

Emanuelsson, O., Brunak, S., von Heijne, G., and Nielsen, H. (2007). Locating proteins in the cell using TargetP, SignalP and related tools. Nat. Protoc. 2, 953-971. doi: 10.1038/nprot.2007.131

Feng, Y., Duan, C. J., Pang, H., Mo, X. C., Wu, C. F., Yu, Y., et al. (2007). Cloning and identification of novel cellulase genes from uncultured microorganisms in rabbit cecum and characterization of the expressed cellulases. Appl. Microbiol. Biotechnol. 75, 319-328. doi: 10.1007/s00253-006-0820-9

Ferrer, M., Ghazi, A., Beloqui, A., Vieites, J. M., López-Cortés, N., Marín-Navarro, J., et al. (2012). Functional metagenomics unveils a multifunctional glycosyl hydrolase from the family 43 catalysing the breakdown of plant polymers in the calf rumen. PLoS One 7:e38134. doi: 10.1371/journal.pone.0038134

Filiatrault-Chastel, C., Navarro, D., Haon, M., Grisel, S., Herpoël-Gimbert, I., Chevret, D., et al. (2019). AA16, a new lytic polysaccharide monooxygenase family identified in fungal secretomes. Biotechnol. Biofuels 12:55. doi: 10.1186/ s13068-019-1394-y

Fontes, C. M., and Gilbert, H. J. (2010). Cellulosomes: highly efficient nanomachines designed to deconstruct plant cell wall complex carbohydrates. Annu. Rev. Biochem. 79, 655-681. doi: 10.1146/annurev-biochem-091208085603

Garg, R., Srivastava, R., Brahma, V., Verma, L., Karthikeyan, S., and Sahni, G. (2016). Biochemical and structural characterization of a novel halotolerant cellulase from soil metagenome. Sci. Rep. 6:39634. doi: 10.1038/srep39634

Gasteiger, E., Hoogland, C., Gattiker, A., Duvaud, S., Wilkins, M. R., Appel, R. D., et al. (2005). "Protein identification and analysis tools on the ExPasy server," in The Proteomics and Protocols Handbook, ed. J. M. Walker (New York, NY: Humana Press), 571-607. doi: 10.1385/1-59259-890-0:571

Gomes, J., and Steiner, W. (2004). The biocatalytic potential of extremophiles and extremozymes. Food Technol. Biotechnol. 42, 223-235.

Graham, J. E., Clark, M. E., Nadler, D. C., Huffer, S., Chokhawala, H. A., Rowland, S. E., et al. (2011). Identification and characterization of a multidomain hyperthermophilic cellulase from an archaeal enrichment. Nat. Commun. 2:375. doi: $10.1038 /$ ncomms 1373

Henrissat, B., Callebaud, I., Fabrega, S., Lehn, P., Mornon, J.-P., and Davies, G. (1995). Conserved catalytic machinery and the prediction of a common fold for several families of glycosyl hydrolases. Proc. Natl. Acad. Sci. U.S.A. 92, 7090-7094. doi: 10.1073/pnas.92.15.7090

Hilge, M., Gloor, S. M., Rypniewski, W., Sauer, O., Heightman, T. D., Zimmermann, W., et al. (1998). High-resolution native and complex structures of thermostable b-mannanase from Thermomonospora fusca - substrate specificity in glycosyl hydrolase family 5. Structure 6, 1433-1444. doi: 10.1016/ s0969-2126(98)00142-7

Horn, S. J., Vaaje-Kolstad, G., Westereng, B., and Eijsink, V. G. H. (2012). Novel enzymes for the degradation of cellulose. Biotechnol. Biofuels 5:45. doi: 10.1186/ 1754-6834-5-45

Hsieh, C. C., Cannella, D., Jorgensen, H., Felby, C., and Thygesen, L. G. (2014). Cellulase inhibition by high concentrations of monosaccharides. J. Agric. Food Chem. 62, 3800-3805. doi: 10.1021/jf5012962

Humphrey, W., Dalke, A., and Schulten, K. (1996). VMD - visual molecular dynamics. J. Mol. Graph. 14, 33-38. doi: 10.1016/0263-7855(96)00018-5

Ito, F., Amano, Y., Nozaki, K., Saxena, M. I, Brown, M. R. Jr., and Kanda, T. (2004). Hydrolysis of water-soluble and water- insoluble cellulosic substrates by endo- $\beta$-1,4-glucanase from Acetobacter xylinum. J. Appl. Glycosci. 51, 297-301. doi: $10.5458 /$ jag. 51.297

Jackson, S. A., Borchert, E., O'Gara, F., and Dobson, A. D. W. (2015). Metagenomics for the discovery of novel biosurfactants of environmental interest from marine ecosystems. Curr. Opin. Biotechnol. 33, 176-182. doi: 10.1016/j.copbio.2015.03.004

Kennedy, J., Marchesi, J. R., and Dobson, A. D. W. (2008). Marine metagenomics: strategies for the discovery of novel enzymes with biotechnological applications from marine environments. Microb. Cell Fact. 7:27. doi: 10.1186/1475-2859-727

Kuhad, R. C., Gupta, R., and Singh, A. (2011). Microbial cellulases and their industrial application. Enzyme Res. 2011:280696. doi: 10.4061/2011/280696

Lambertz, C., Garvey, M., Klinger, J., Heesel, D., Klose, H., Fischer, R., et al. (2014). Challenges and advances in the heterologous expression of cellulolytic enzymes: a review. Biotechnol. Biofuels 7:135. doi: 10.1186/s13068-014-0135-5

Lee, C. M., Lee, Y. S., Seo, S. H., Yoon, S. H., Kim, S. J., Hahn, B. S., et al. (2014). Screening and characterization of a novel cellulase gene from the gut microflora of Hermetia illucens using metagenomic library. J. Microbiol. Biotechnol. 24, 1196-1206. doi: 10.4014/jmb.1405.05001

Li, L. L., McCorkle, S. R., Monchy, S., Taghavi, S., and van der Lelie, D. (2009). Bioprospecting metagenomes: glycosyl hydrolases for converting biomass. Biotechnol. Biofuels 2:10. doi: 10.1186/1754-6834-2-10

Li, L. L., Taghavi, S., McCorkle, S. M., Zhang, Y. B., Blewitt, M. G., Brunecky, R., et al. (2011). Bioprospecting metagenomics of decaying wood: mining for new glycoside hydrolases. Biotechnol. Biofuels 4:23. doi: 10.1186/1754-6834-4-23

Li, W., Cowley, A., Uludag, M., Gur, T., McWilliam, H., Squizzato, S., et al. (2015). The EMBL-EBI bioinformatics web and programmatic tools framework. Nucleic Acids Res. 43, W580-W584. doi: 10.1093/nar/gkv279

Lin, L., Liu, X., Zhou, Y., Guan, L., He, J., and Huang, W. (2016). A novel pH-stable, endoglucanase (JqCel5A) isolated from a salt-lake microorganism, Jonesia quinghaiensis. Electron. J. Biotechnol. 24, 56-62. doi: 10.1016/j.ejbt.2016.09.004

Liu, J., Liu, W., Zhao, X., Shen, W., Cao, H., and Cui, Z. (2010). Cloning and functional characterization of a novel endo- $\beta$-1,4-glucanase gene from a soil-derived metagenomic library. Appl. Microbiol. Biotechnol. 89, 1083-1092. doi: 10.1007/s00253-010-2828-4

Lombard, V., Golaconda Ramulu, H., Drula, E., Coutinho, P. M., and Henrissat, B. (2014). The Carbohydrate-active enzymes database (CAZy) in 2013. Nucleic Acids Res. 42, D490-D495. doi: 10.1093/nar/gkt1178

Mahadevan, S. A., Wi, S. G., Lee, D. S., and Bae, H. J. (2008). Site-directed mutagenesis and CBM engineering of Cel5A (Thermotoga maritima). FEMS Microbiol. Lett. 287, 205-211. doi: 10.1111/j.1574-6968.2008.01324.x 
Marchler-Bauer, A., Derbyshire, M. K., Gonzales, N. R., Lu, S., Chitsaz, F., Geer, L. Y., et al. (2015). CDD: NCBI's conserved domain database. Nucleic Acids Res. 43, 222-226. doi: 10.1093/nar/gku1221

Martin, M., Biver, S., Steels, S., Barbeyron, T., Jam, M., Portetelle, D., et al. (2014). Identification and characterization of a halotolerant, cold active marine endo- $\beta$-1,4-glucanase by using functional metagenomics of seaweed-associated microbiota. Appl. Environ. Microbiol. 80, 4958-4967. doi: 10.1128/AEM. 01194-14

McWilliam, H., Li, W., Uludag, M., Squizzato, S., Park, Y. M., Buso, N., et al. (2013). Analysis tool web services from the EMBL-EBI. Nucleic Acids Res. 41, W597-W600. doi: 10.1093/nar/gkt376

Mendes, R., Garbeva, P., and Raaijmakers, J. M. (2013). The rhizosphere microbiome: significance of plant beneficial, plant pathogenic, and human pathogenic microorganisms. FEMS Microbiol. Rev. 37, 634-663. doi: 10.1111/ 1574-6976.12028

Meneses, C., Silva, B., Medeiros, B., Serrato, R., and Johnston-Monje, D. (2016). A metagenomic advance for the cloning and characterization of a cellulase from red rice crop residues. Molecules 21:E831. doi: 10.3390/molecules21070831

Miller, G. L. (1959). Use of dinitro-salicylic acid reagent for determination of reducing sugars. Anal. Chem. 31, 426-428. doi: 10.1021/ac60147a030

Mori, T., Kamei, I., Hirai, H., and Kondo, R. (2014). Identification of novel glycosyl hydrolases with cellulytic activity against crystalline cellulose from metagenomic libraries constructed from bacterial enrichment cultures. Springerplus 3:365. doi: 10.1186/2193-1801-3-365

Naas, A. E., MacKenzie, A. K., Dalhus, B., Eijsink, V. G. H., and Pope, P. B. (2015). Structural features of a bacteroidetes-affiliated cellulase linked with a polysaccharide utilization locus. Sci. Rep. 5:11666. doi: 10.1038/srep11666

Nacke, H., Engelhaupt, M., Brady, S., Fischer, C., Tautzt, J., and Daniel, R. (2012). Identification and characterization of novel cellulolytic and hemicellulolytic genes and enzymes derived from German grassland soil metagenomes. Biotechnol. Lett. 34, 663-675. doi: 10.1007/s10529-011-0830-2

Noguchi, H., Park, J., and Takagi, T. (2006). MetaGene: prokaryotic gene finding from environmental genome shotgun sequences. Nucleic Acids Res. 34, 5623-5630. doi: 10.1093/nar/gkl723

O’Mahony, M. M., Henneberger, R., Selvin, J., Kennedy, J., Doohan, F., Marchesi, J. R., et al. (2015). Inhibition of the growth of Bacillus subtilis DSM10 by a newly discovered antibacterial protein from the soil metagenome. Bioengineered 6, 89-98. doi: 10.1080/21655979.2015.1018493

Pakarinen, A., Haven, M. Ø., Djajadi, D. T., Várnai, A., Puranen, T., and Viikari, L. (2014). Cellulases without carbohydrate-binding modules in high consistency ethanol production process. Biotechnol. Biofuels 7:27. doi: 10.1186/17546834-7-27

Pereira, J. H., Chen, Z., McAndrew, R., Sapra, R., Chhabra, S. R., Sale, K. L., et al. (2010). Biochemical characterization and crystal structure of endoglucanase Cel5A from the hyperthermophilic Thermotoga maritima. J. Struct. Biol. 172, 372-379. doi: 10.1016/j.jsb.2010.06.018

Pérez, J., Muñoz-Dorado, J., de la Rubia, T., and Martßnez, J. (2002). Biodegradation and biological treatments of cellulose, hemicellulose and lignin: an overview. Int. Microbiol. 5, 53-63. doi: 10.1007/s10123-002-0062-3

Petersen, T. N., Brunak, S., von Heijne, G., and Nielsen, H. (2011). SignalP 4.0: discriminating signal peptides from transmembrane regions. Nat. Methods 8, 785-786. doi: 10.1038/nmeth.1701

Pimentel, A. C., Ematsu, G. C. G., Liberato, M. V., Paixão, D. A. A., Franco Cairo, J. P. L., Mandelli, F., et al. (2017). Biochemical and biophysical properties of a metagenome-derived GH5 endoglucanase displaying an unconventional domain architecture. Int. J. Biol. Macromol. 99, 384-393. doi: 10.1016/j. ijbiomac.2017.02.075

Reyes-Ortiz, V., Heins, R. A., Cheng, G., Kim, E. Y., Elandt, R. B., et al. (2013). Addition of a carbohydrate-binding module enhances cellulase penetration into cellulose substrates. Biotechnol. Biofuels 6:93. doi: 10.1186/1754-6834-6-93

Rice, P., Longden, I., and Bleasby, A. (2000). EMBOSS: the european molecular biology open software suite. Trends Genet. 16, 276-277. doi: 10.1016/s01689525(00)02024-2

Roy, A., Kucukural, A., and Zhang, Y. (2010). I-TASSER: a unified platform for automated protein structure and function prediction. Nat. Protoc. 5, 725-738. doi: $10.1038 /$ nprot.2010.5

Ryu, S., and Karim, M. N. (2011). A whole cell biocatalyst for cellulosic ethanol production from dilute acid-treated corn stover hydrolysates. Appl. Microbiol. Biotechnol. 91, 529-542. doi: 10.1007/s00253-011-3261-z
Sharma, A., Tewari, R., Rana, S. S., Soni, R., and Soni, S. K. (2016). Cellulases: classification, methods of determination and industrial applications. Appl. Biochem. Biotechnol. 179, 1346-1380. doi: 10.1007/s12010-016-2070-3

Stivala, A., Wybrow, M., Wirth, A., Whisstock, J. C., and Stuckey, P. J. (2011). Automatic generation of protein structure cartoons with Pro-origami. Bioinformatics 27, 3315-3316. doi: 10.1093/bioinformatics/btr575

Sukumaran, R. K., Singhania, R. R., and Pandey, A. (2005). Microbial cellulases production, applications and challenges. J. Sci. Ind. Res. 64, 832-844.

Tamura, K., Stecher, G., Peterson, D., Filipski, A., and Kumar, S. (2013). MEGA6: Molecular evolutionary genetics analysis version 6.0. Mol. Biol. Evol. 30 , 2725-2729. doi: 10.1093/molbev/mst197

Tiwari, R., Nain, L., Labrou, N. E., and Shukla, P. (2018). Bioprospecting of functional cellulases from metagenome for second generation biofuel production: a review. Crit. Rev. Microbiol. 44, 244-257. doi: 10.1080/1040841X. 2017.1337713

Vester, J. K., Glaring, M. A., and Stougaard, P. (2014). Discovery of novel enzymes with industrial potential from a cold and alkaline environment by a combination of functional metagenomics and culturing. Microb. Cell Fact. 13:72. doi: $10.1186 / 1475-2859-13-72$

Voget, S., Steele, H. L., and Streit, W. R. (2006). Characterization of a metagenomederived halotolerant cellulose. J. Biotechnol. 126, 26-36. doi: 10.1016/j.jbiotec. 2006.02.011

Walker, J. M. (2002). The Protein Protocols Handbook, 2nd Edn. Totowa, NJ: Humana Press.

Wang, Y., Tang, R., Tao, J., Wang, X., Zheng, B., and Feng, Y. (2012). Chimeric cellulase matrix for investigating intramolecular synergism between nonhydrolytic disruptive functions of carbohydrate-binding modules and catalytic hydrolysis. J. Biol. Chem. 287, 29568-26878. doi: 10.1074/jbc.M111.320358

Wang, Y., Wang, X., Tang, R., Yu, S., Zheng, B., and Feng, Y. (2010). A novel thermostable cellulase from Fervidobacterium nodosum. J. Mol. Catal. B Enzym. 66, 294-301. doi: 10.1016/j.molcatb.2010.06.006

Wu, T. H., Huang, C. H., Ko, T. P., Lai, H. L., Ma, Y., Chen, C. C., et al. (2011). Diverse substrate recognition mechanism revealed by Thermotoga maritima Cel5A structures in complex with cellotetraose, cellobiose and mannotriose. Biochim. Biophys. Acta 1814, 1832-1840. doi: 10.1016/j.bbapap.2011.07.020

Xing, M. N., Zhang, X. Z., and Huang, H. (2012). Application of metagenomic techniques in mining enzymes from microbial communities for biofuel synthesis. Biotechnol. Adv. 30, 920-929. doi: 10.1016/j.biotechadv.2012.01.021

Yang, C., Xia, Y., Qu, H., Li, A. D., Liu, R., Wang, Y., et al. (2016). Discovery of new cellulases from the metagenome by a metagenomics-guided strategy. Biotechnol. Biofuels 9:138. doi: 10.1186/s13068-016-0557-3

Yuan, S. F., Wu, T. H., Lee, H. L., Hsieh, H. Y., Lin, W. L., Yang, B., et al. (2015). Biochemical characterization and structural analysis of a bifunctional cellulase/xylanase from Clostridium thermocellum. J. Biol. Chem. 290, 5739-5748. doi: 10.1074/jbc.M114.604454

Zhang, C., and Kim, S. K. (2010). Research and application of marine microbial enzymes: status and prospects. Mar. Drugs 8, 1920-1934. doi: 10.3390/ md8061920

Zhang, L., Fan, Y., Zheng, H., Du, F., Zhang, K., Huang, X., et al. (2013). Isolation and characterization of a novel endoglucanase from a Bursaphelenchus xylophilus metagenomic library. PLoS One 8:e82437. doi: 10.1371/journal.pone. 0082437

Zheng, B., Yang, W., Zhao, X., Wang, Y., Lou, Z., Rao, Z., et al. (2012). Crystal Structure of hyperthermophilic endo- $\beta-1,4$-glucanase. J. Biol. Chem. 287, 8336-8346. doi: 10.1074/jbc.M111.266346

Zhou, Y., Wang, X., Wei, W., Xu, J., Wang, W., Xie, Z., et al. (2016). A novel efficient $\beta$-glucanase from a paddy soil microbial metagenome with versatile activities. Biotechnol. Biofuels 9:36. doi: 10.1186/s13068-016-0449-6

Conflict of Interest Statement: The authors declare that the research was conducted in the absence of any commercial or financial relationships that could be construed as a potential conflict of interest.

Copyright () 2019 Wierzbicka-Woś, Henneberger, Batista-García, Martínez-Ávila, Jackson, Kennedy and Dobson. This is an open-access article distributed under the terms of the Creative Commons Attribution License (CC BY). The use, distribution or reproduction in other forums is permitted, provided the original author(s) and the copyright owner(s) are credited and that the original publication in this journal is cited, in accordance with accepted academic practice. No use, distribution or reproduction is permitted which does not comply with these terms. 